Check for updates

Cite this: J. Mater. Chem. A, 2021, 9 , 20919

Received 28th May 2021

Accepted 26th August 2021

DOI: $10.1039 / \mathrm{d} 1 \mathrm{ta} 04527$

rsc.li/materials-a

\section{Optoelectronic devices based on the integration of halide perovskites with silicon-based materials}

\begin{abstract}
Jingjing Liu, ab Junle Qu, (D) a Thomas Kirchartz (D) *bc and Jun Song (D)*a
Halide perovskites are widely used as an absorbing or emitting layer in emerging high-performance optoelectronic devices due to their high absorption coefficients, long charge carrier diffusion lengths, low defect density and intense photoluminescence. Si-based materials (c-Si, a-Si, $\mathrm{Si}_{x} \mathrm{~N}_{y}, \mathrm{SiC}_{x}$ and $\mathrm{SiO}_{2}$ ) play important roles in high performance perovskite optoelectronic devices due to the dominance of Sibased microelectronics and the important role of Si-based solar cells in photovoltaics. Controlling the preparation of perovskite materials on the dominant Si optoelectronics platform is a crucial step to realize practical perovskite-based optoelectronic devices. This review highlights the recent progress in Si-based perovskite optoelectronic devices including perovskite/Si tandem solar cells, perovskite/Si photodetectors, perovskite/Si light emitting diodes and optically pumped lasers. The remaining challenge in Si-based perovskite optoelectronic devices research are discussed.
\end{abstract}

\section{Introduction}

Silicon has been the cornerstone of microelectronics and photovoltaics (PV) for decades and is thereby central to the key technologies of digitalization and renewable energies that will shape the $21^{\text {st }}$ century. ${ }^{1-3}$ Silicon has a multitude of advantages

${ }^{a}$ Center for Biomedical Optics and Photonics (CBOP), College of Physics and Optoelectronic Engineering, Key Laboratory of Optoelectronic Devices and Systems, Shenzhen University, 518060 Shenzhen, P. R. China. E-mail: songjun@szu.edu.cn ${ }^{b}$ IEK5-Photovoltaics, Forschungszentrum Jülich, 52425 Jülich, Germany. E-mail: $t$. kirchartz@fz-juelich.de

${ }^{c}$ Faculty of Engineering and CENIDE, University of Duisburg-Essen, Carl-Benz-Strasse 199, 47057 Duisburg, Germany

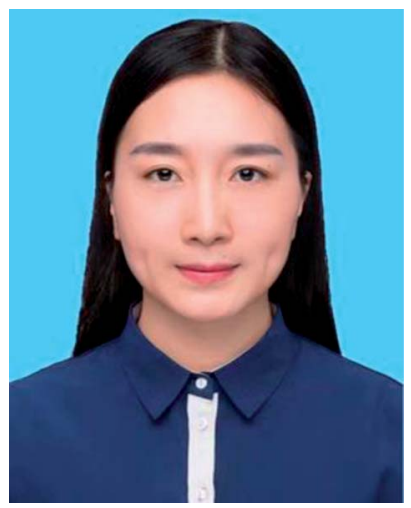

Jingjing Liu obtained her M.S. degree from Henan University in 2016 and PhD degree from the Nanjing University in 2019. She subsequently joined Shenzhen University as a postdoctoral researcher. She is currently a Visiting Scholar with Professor Thomas Kirchartz at the Research Centre Jülich (Institute for Energy and Climate Research), Germany. Her research interests are semiconductor self-assembled monolayer materials and their applications in perovskite solar cells. with the most important being our ability to grow huge monocrystalline $\mathrm{Si}$ crystals with excellent electronic properties, a near-perfect band gap for photovoltaics and a native oxide that protects the surface rather than making it rust like iron. There are only few disadvantages of silicon and they are related to the indirect nature of its band gap. The indirect band gap slows down radiative recombination and therefore makes it impossible to achieve Si-based light emitting diodes with a similar luminescence quantum efficiency as those made from III-V semiconductors such as GaAs. ${ }^{4-6}$ In addition, the indirect band gap reduces the absorption coefficient and therefore has prohibited the fabrication of highly efficient thin-film silicon solar cells. However, for the field of photovoltaics, the indirect band

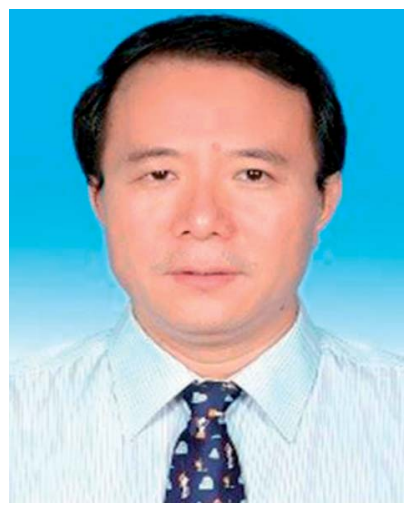

Junle Qu is currently the dean of the College of Optoelectronic Engineering and the director of the Key Laboratory of Optoelectronic Devices and Systems of the Education Ministry, Shenzhen University. He is an SPIE fellow member and the chairman of the Biomedical Photonics Specialized Committee of the Chinese Optical Society. His research focuses on fluorescence lifetime imaging, NIR-II imaging, super-resolution imaging, etc. He is leading 15 research projects, including the National Outstanding Youth Fund Project of China, the National Plan on Key Basic Research and Development, etc. 
gap has not been a show-stopper. On the contrary, it hardly creates a problem if combined with the wafer-based "first generation" approach to Si photovoltaics that has been very successful both scientifically and economically over the last years. Maybe the only real shortcoming of $\mathrm{Si}$ as a photovoltaic material is that we don't have two semiconductors like Si with different band gaps. In photovoltaics, a substantial amount of energy is lost by thermalization or sub-band gap transmission of photons. ${ }^{7}$ Which of the two mechanisms is more relevant depends on the band gap and as long as there is only one semiconductor involved, solar cell efficiencies under unconcentrated sunlight will not exceed the 33\% efficiency limit given by the Shockley-Queisser (SQ) model. ${ }^{8}$ Reducing the losses would only work in devices that make use of two or more different band gaps (multijunction solar cells). ${ }^{9}$ Until quite recently however, it has been impossible to fabricate efficient tandem solar cells with Si-based low band gap cells. The only suitable top cell material would have been GaInP which would have added a substantial cost to the system. ${ }^{\mathbf{1 0}} \mathrm{A}$ cheap and efficient high band gap material wasn't known. This situation changed drastically with the advent of the halide perovskite material family. Several halide perovskites were found and investigated that have exceptional electronic and optoelectronic properties, can be processed from solution, form with a range of different band gaps and have excellent luminescent and photovoltaic properties. ${ }^{11-19}$ Halide perovskites have a nearunique combination of exciting properties that could make them an ideal partner for silicon and extend its capabilities by enabling tandem solar cells or optoelectronic devices that can be integrated into silicon-based microelectronics. There are however also substantial challenges for the application of halide perovskites, namely issues with material and device stability, a combination of ionic and electronic conduction that leads to metastable behaviour and the fact that the toxic element lead is used in those halide perovskites that have the best optoelectronic properties. ${ }^{20-22}$

Here, we will critically review and present the current status of the integration of these two material systems and discuss the progress in developing applications that rely on the complementarity of the properties of Si and halide perovskites. Fig. 1 gives an overview over the key topics and device types that we will discuss in this review. The schematic illustration of perovskite/Si tandem solar cells is shown in Fig. 1a. Perovskites with wide bandgaps around $1.65 \mathrm{eV}$ to $1.75 \mathrm{eV}$ (ref. 23 and 24) are used as top cell to absorb the short wavelength spectrum. Crystalline Si has a band gap of $1.12 \mathrm{eV}$ and is used as bottom cell to absorb the long wavelength spectrum transmitted by the top cell.

Fig. 1b shows the schematic illustration of perovskite/Si field-effect transistor-based photodetectors. $\mathrm{SiO}_{2}$ are not only used as dielectric layers to passivate interface in perovskite/Si tandem, but also work as dielectrics to form a $\mathrm{SiO}_{2} / \mathrm{Si}$ capacitor in such perovskite/Si photodetectors. The band bending at the $\mathrm{Si} / \mathrm{SiO}_{2}$ interface creates an electric field that effectively separates the optically generated electron-hole pairs in Si. In order to improve the responsivity, low-dimensional perovskites i.e. nanoplates, nanorods, nanowires and quantum dots were combined with Si to fabricate photodetectors with unique structures and photoelectric properties. Fig. 1c shows an example of a light emitting diode based on a perovskite emission layer deposited on top of a p-type silicon substrate that serves to inject holes into the perovskite. Using a structure like that, Liu et al. reported Si-based all inorganic perovskite LEDs with emission wavelengths of $515 \mathrm{~nm}$ and $681 \mathrm{~nm} .{ }^{25}$ Furthermore, $\mathrm{Xu}$ et al. used a similar design to fabricate Si-based

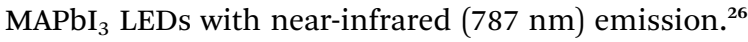

Fig. 1d shows the schematic illustration of an optically pumped perovskite/Si laser as reported e.g. in ref. 27. The design shown in Fig. 1d is based on the deposition of a perovskite layer on top of a periodically patterned Si wafer that was covered with $\mathrm{Si}_{x} \mathrm{~N}_{y}$ or $\mathrm{SiO}_{2}$. The purpose of the patterning as discussed in ref. 28 is to reduce the lasing threshold and the emission linewidth by reducing the roughness and providing better light confinement.

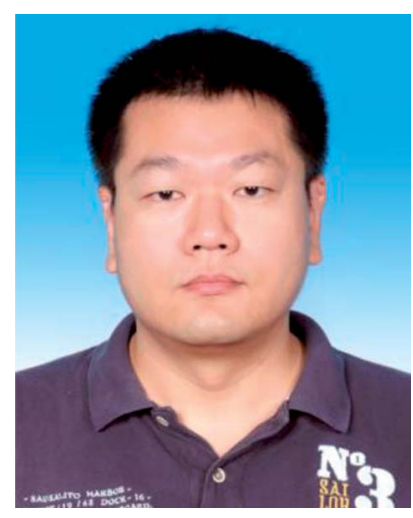

Jun Song received his B.Eng. degree in information engineering from Zhejiang University. Then, he received his $P h D$ degrees from Zhejiang University and Royal Institute of Technology, respectively. $\mathrm{He}$ is currently a Professor of Biomedical Photonics \& College of Physics and Optoelectronic Engineering, Shenzhen University. His currently research focus on nanophotonics as well as its applications in renewable energy, biomedicine, electronic information, and environmental protection. research interests include all aspects regarding the fundamental understanding of photovoltaic devices including their characterization and simulation. 


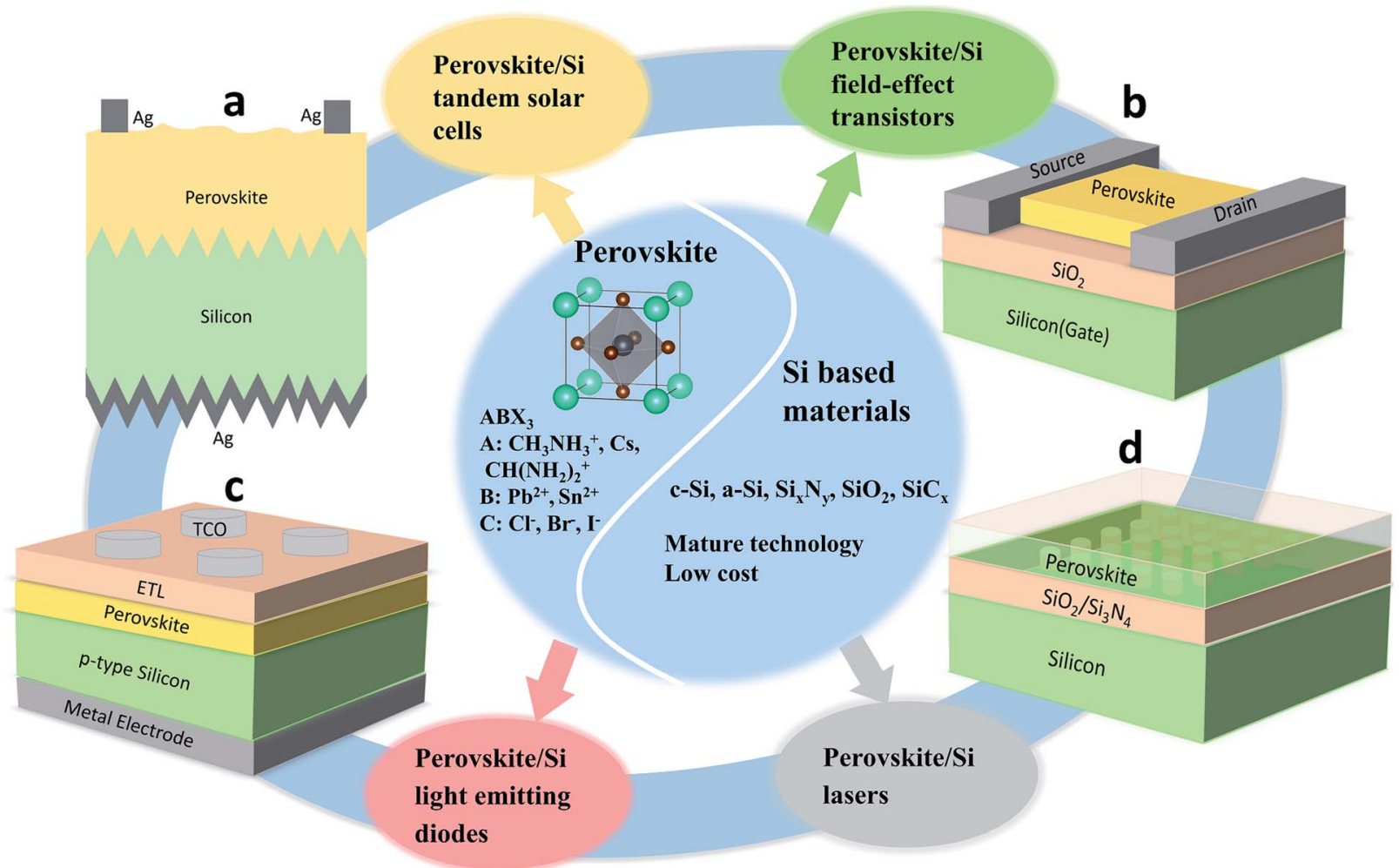

Fig. 1 Schematic illustration of Si-based perovskite optoelectronic devices include (a) perovskite/Si tandem solar cells, (b) perovskite/Si fieldeffect transistor based photodetector, (c) perovskite/Si light emitting diodes and (d) Si-based perovskite lasers.

\section{Perovskite/Si tandem solar cells}

The efficiency of single junction (SJ) solar cells illuminated with unconcentrated sunlight is limited to the fundamental SQ limit of $31-33 \% .^{8}$ The exact value of the SQ limit depends on the spectrum used with many recent publications using the AM1.5G spectrum that is specified in the standard testing conditions for terrestrial solar cells and leads to $\approx 33 \%$ (see Fig. 2a). However, the original paper used a $6000 \mathrm{~K}$ black body spectrum which then leads to $\approx 31 \%$. As shown in Fig. 2 a, the maximum efficiency is reached or nearly reached for a range of band gaps around 1.1-1.45 eV (ref. 29 and 30) which includes most technologically important semiconductors for photovoltaics such as crystalline $\mathrm{Si}$ (record efficiency 26.7\%), ${ }^{29,31} \mathrm{Cu}(\mathrm{In}, \mathrm{Ga}) \mathrm{Se}_{2}$ (record efficiency $23.35 \%$ ), ${ }^{29,32}$ many organic solar cell blends (record efficiency 18.2\%), ${ }^{33,34}$ GaAs (record efficiency $29.1 \%$ ), ${ }^{29,35} \mathrm{CdTe}$
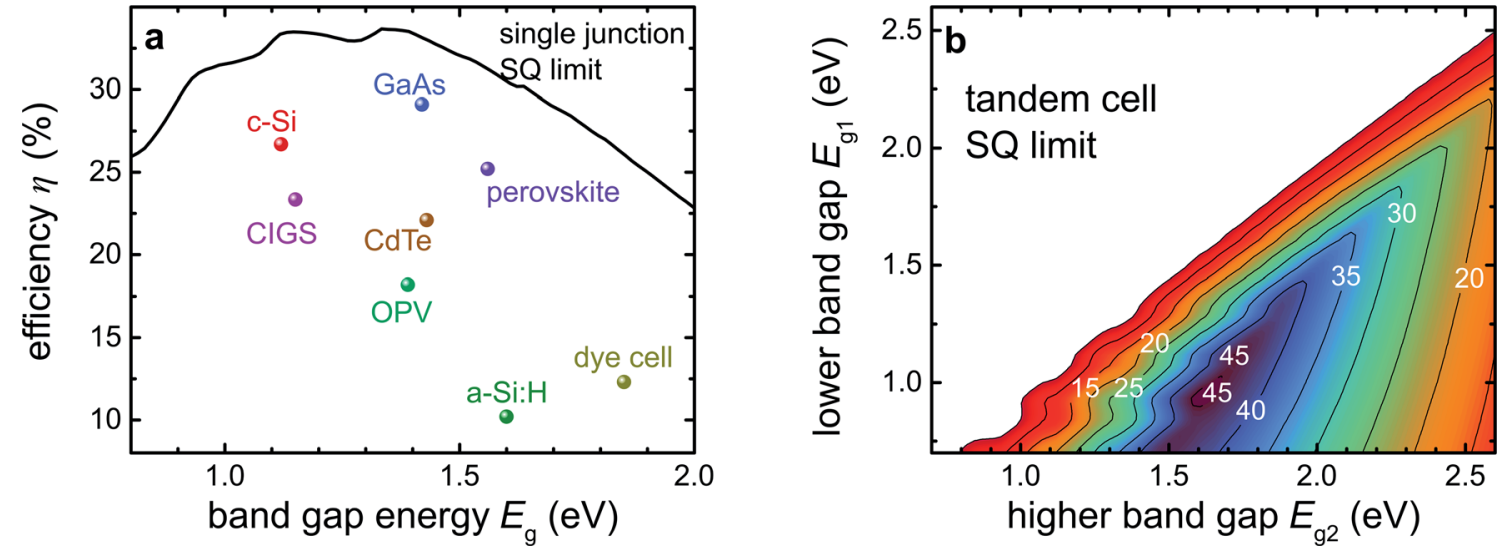

Fig. 2 (a) Thermodynamic limit of photovoltaic conversion efficiency for single junction solar cells as a function of band gap (Shockley-Queisser limit) compared to best practically achieved efficiencies for different photovoltaic technologies. ${ }^{30-39}$ (b) Thermodynamic limit of photovoltaic conversion efficiency for tandem solar cells as a function of the two band gaps. Theoretically, efficiencies up to $45 \%$ are possible with tandem cells as compared to $33 \%$ for single junction solar cells. Panel (b) reproduced with permission. ${ }^{41}$ Copyright 2018, Wiley-VCH. 
(record efficiency $22.1 \%) .{ }^{\mathbf{2 9 , 3 6}}$ Only lead halide perovskites (record efficiency 25.5\%), ${ }^{\mathbf{2 9}, 38}$ a-Si : H (record efficiency $10.2 \%)^{29,39}$ and most dye-sensitized solar cells ${ }^{29,34,37}$ have band gaps that are slightly too high to be in the optimal region. While lead-halide perovskites can span a fairly wide range of band gaps, the compositions leading to the highest solar cell efficiencies can be found in the tight range between 1.5 and $1.65 \mathrm{eV}^{40}$

Fig. $2 \mathrm{~b}$ shows the thermodynamic limit of photovoltaic conversion efficiency for tandem solar cells as a function of the two band gaps. The thermodynamic efficiency limit for tandem solar cells is around 45\% (ref. 41) and practical efficiencies may substantially exceed $30 \%$ (ref. 42 and 43 ) in the future. Combining the band gaps around $E_{\mathrm{g}} \approx 1.1 \mathrm{eV}$ of silicon with band gaps in the range of $E_{\mathrm{g}} \approx 1.75 \mathrm{eV}$ would then lead to the highest efficiencies in theory. Recently, the certified conversion efficiency of single junction perovskite solar cell has reached 25.5\% (ref. 29 and 38) (Fig. 3, black line, data from National Renewable Energy Laboratory (NREL)) while the best efficiencies that have been published in scientific journals are currently $25.4 \%{ }^{44}$ and $25.6 \% .^{45}$ However, note that the recent record efficiencies have nearly all been reached with compositions that are closer to the lower end of band gaps mentioned above (1.5 $\mathrm{eV}$ ). While this trend towards lower band gaps makes sense from looking at Fig. 2a, it does not immediately benefit the search for higher efficiency tandem solar cells.

The energy conversion efficiency of silicon solar cells in the lab reached a record value of 26.7\% in 2017 (ref. 29 and 31) (orange dotted line in Fig. 3, data from NREL) which is vital to obtain high efficiency perovskite tandem solar cell. However, these efficiencies have been reached with intermediate back contact solar cells that have both anode and cathode at the back of the cell and no metallization at the front. While this design brings obvious benefits for increasing the short-circuit current density in single junction solar cells, it is not compatible with the widely studied two-terminal tandem cells where anode and cathode are on opposite sides of the tandem cell. The best (single junction) efficiency of a double-side contacted Si solar cell compatible with two-terminal tandem designs is currently $26 \%{ }^{46}$

The goal of achieving high efficiency Si-based tandem solar cells is challenging because of the requirement of band gap matching that is necessary for two-terminal (2-T) tandem solar cells and that depends on factors such as location and climate of the photovoltaic installation, bifaciality of the system, temperature of the cell ${ }^{23}$ and the amount of optical coupling between the two subcells. ${ }^{47,48}$ This implies that depending on the exact design of the tandem cell as well as on the position on the globe or the type of installation slightly different perovskite compositions would give the optimum annual yield. Hence research has to target the optimization of perovskite solar cells with a range of band gaps between approximately 1.65 to $1.75 \mathrm{eV}$. Substantial research efforts have recently been directed towards exploring the possibilities to make efficient perovskiteSi tandem solar cells leading to an efficiency (under standard testing conditions and monofacial illumination) exceeding $29 \%{ }^{49-52}$ The efficiency of perovskite/Si tandem solar cells (green dotted line in Fig. 3, data from NREL) is therefore already substantially higher than the efficiency of single junction solar cells made from either perovskite or silicon absorber layers.

Fig. 4 plots the tandem solar cell parameters (short-circuit current density $\left(J_{\mathrm{sc}}\right)$, open-circuit voltage $\left(V_{\mathrm{oc}}\right)$ and fill factor (FF)) as a function of power conversion efficiency (PCE) for those cells listed in Table 1. It is clear that the increased PCE is directly caused by the enhanced $V_{\mathrm{oc}}$ and $J_{\mathrm{sc}}$. In Fig. 4 , the highest PCE for perovskite/Si tandem solar cells is $29.15 \%$, together with $1.90 \mathrm{~V} V_{\mathrm{oc}}, 79.4 \% \mathrm{FF}$ and $J_{\mathrm{sc}}$ of $19.23 \mathrm{~mA} \mathrm{~cm}^{-2}$ (ref. 53) (see line 20 in Table 1). In order to further improve the performance, both the top cell absorption and bottom silicon cell technology are important choices in the design of perovskite/Si tandem solar cell. In this section, we focus on the architecture of

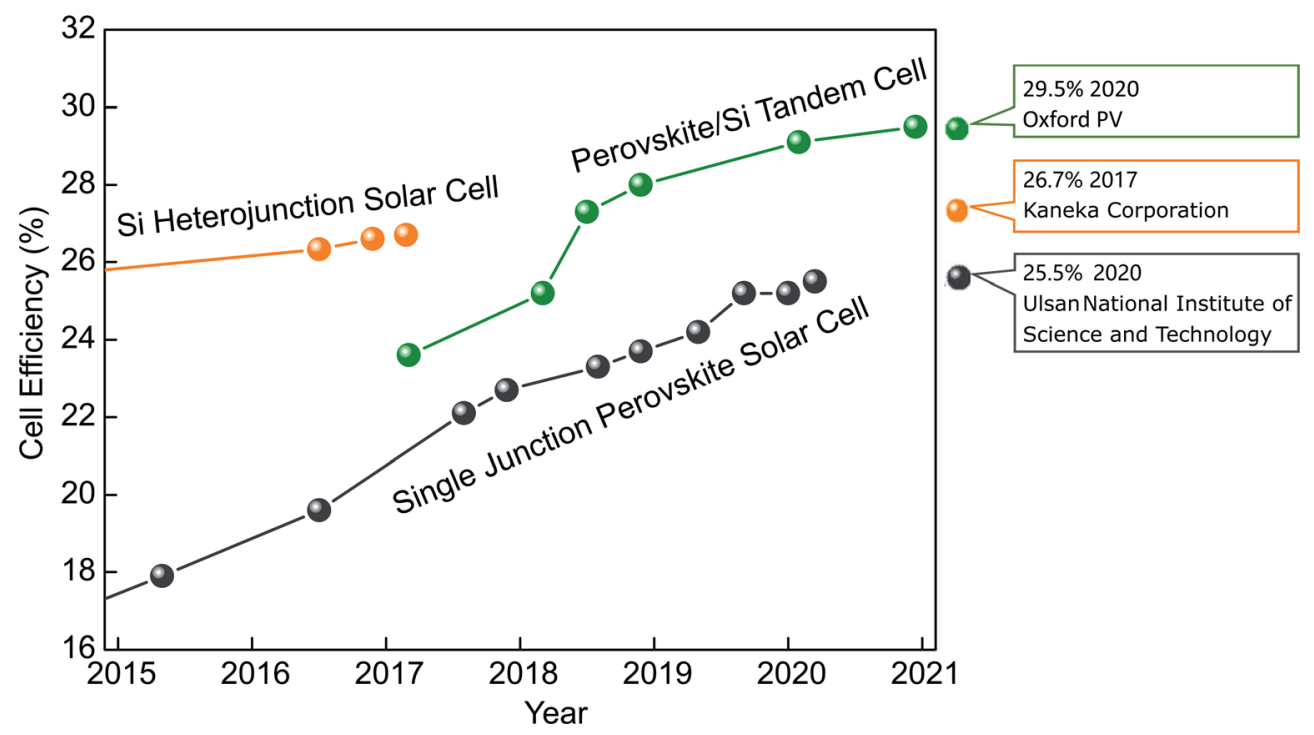

Fig. 3 Record efficiency evolution over the last five years for silicon heterojunction solar cell (26.7\% by Kaneka Corporation), single junction perovskite solar cell (25.5\% by Ulsan National Institute of Science and Technology), perovskite/Si tandem cell ( $29.5 \%$ by Oxford PV). 


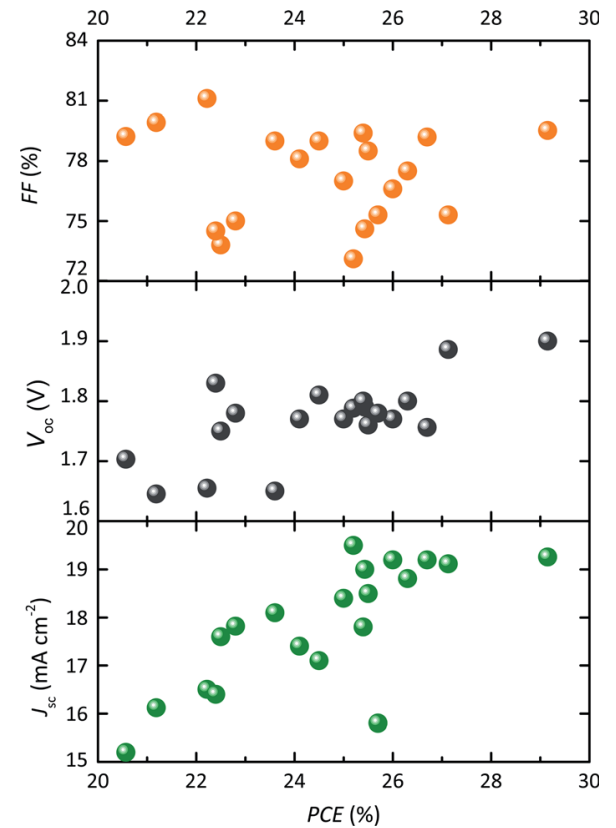

Fig. 4 Summary of $J-V$ parameters from Table $1 . J_{\mathrm{sc}}, V_{\mathrm{oc}}$ and $\mathrm{FF}$ as a function of PCE, respectively.

optimizing the current matching between the top cell and the bottom cell. We summarize various approaches to enhance absorption and reduce the optical loss between Si sub cell and the perovskite cell.

\subsection{Wide band gap perovskite to top solar cell}

In tandem solar cells, good current matching between the top cell and the bottom cell is the key condition for achieving a higher efficiency stacked cell than a single junction cell. The crystalline $\mathrm{Si}$ has a band gap of $1.12 \mathrm{eV}$, in order to currentmatch both junctions, a top cell material with a band gap of $1.73 \mathrm{eV}$ is required under standard test conditions (AM1.5G spectrum, $\left.1000 \mathrm{~W} \mathrm{~m}^{-2} 25{ }^{\circ} \mathrm{C}\right){ }^{8,67-69}$ The band gap of typical single-junction perovskite devices is usually lower than $1.73 \mathrm{eV}^{70-73}$ To achieve the highest efficiencies, the current approach is to go for double or triple cation materials with a double anion (i.e. mixture of $\mathrm{I}$ and $\mathrm{Br}$ ). Relative to the prototypical $\mathrm{MAPb}_{3}$, formamidinium (FA) reduces the band gap, while $\mathrm{Cs}$ as a cation and $\mathrm{Br}$ as a partial replacement for I as an anion increase the band gap. A typical composition that gives suitable band gaps is e.g. the double cation composition $\mathrm{FA}_{0.83} \mathrm{Cs}_{0.17} \mathrm{~Pb}\left(\mathrm{I}_{0.6} \mathrm{Br}_{0.4}\right)_{3}$ with $1.74 \mathrm{eV}$ band gap. A four-terminal tandem cell with over $25 \%$ efficient was achieved by combining $\mathrm{FA}_{0.83} \mathrm{Cs}_{0.17} \mathrm{~Pb}\left(\mathrm{I}_{0.6} \mathrm{Br}_{0.4}\right)_{3}$ cells with a $19 \%$ efficient silicon cell. ${ }^{74}$ So far the highest published efficiencies in 2-T tandem cells were achieved with a triple-cation perovskite with the composition $\mathrm{FA}_{0.5} \mathrm{MA}_{0.38} \mathrm{Cs}_{0.12} \mathrm{PbI}_{2.04} \mathrm{Br}_{0.96}$ with $1.69 \mathrm{eV}$ band gap. ${ }^{53}$ In their work, a 2-T tandem device based on a siliconheterojunction bottom cell showed over $29 \%$ efficiency with the efficiency increase relative to earlier attempts being largely due to the application of novel self-assembled monolayers (SAMs) as ultra thin hole transport layers (see Fig. 5 a and line 20 in Table 1). These SAMs allowed higher fill factors due to the reduction in resistive losses and improved open circuit voltages due to better energy level alignment. At the same time, some research has focused on cation components of the $2 \mathrm{D}$ additives. Kim et al. developed a 2D-3D mixed wide band gap perovskite by using a mixture of thiocyanate with the more-conventional choice, iodine. The prepared monolithic perovskite-silicon tandem solar cell obtains an efficiency of $26.7 \%$ and excellent

Table 1 Summary of the composition and device performance of perovskite/Si tandem solar cells ${ }^{a}$

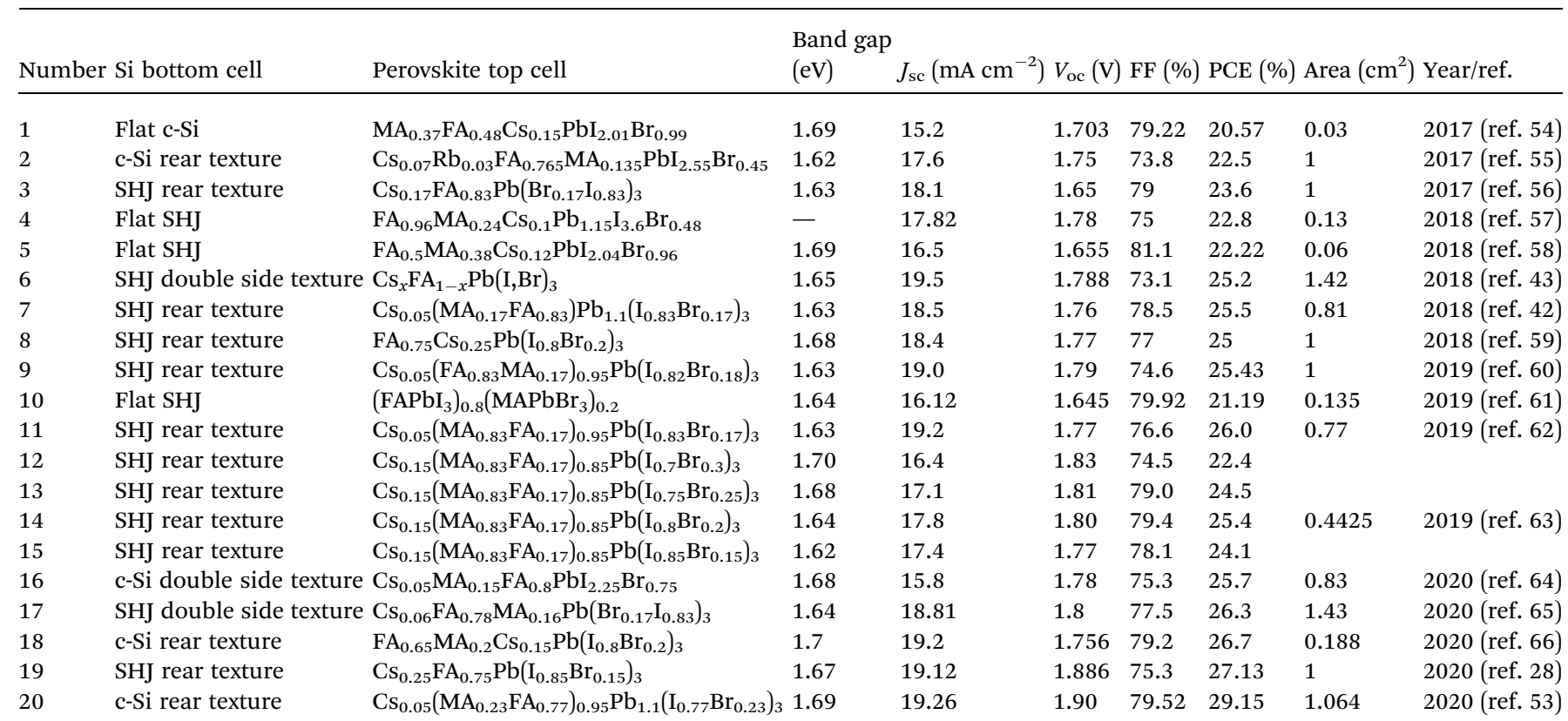

${ }^{a}-$, not reported; $\mathrm{SHJ}$ is silicon heterojunction; $\mathrm{MA}$ is $\mathrm{CH}_{3} \mathrm{NH}_{3}{ }^{+}$; $\mathrm{FA}$ is $\mathrm{CH}\left(\mathrm{NH}_{2}\right)_{2}{ }^{+}$. 


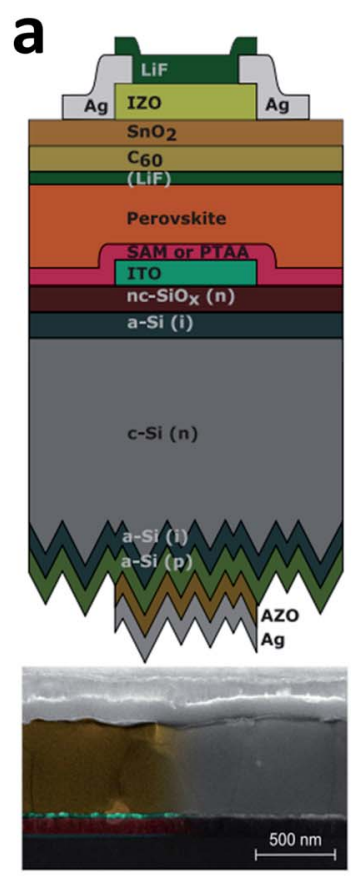

A. Al-Ashouri et al, PCE $29.15 \%$

b

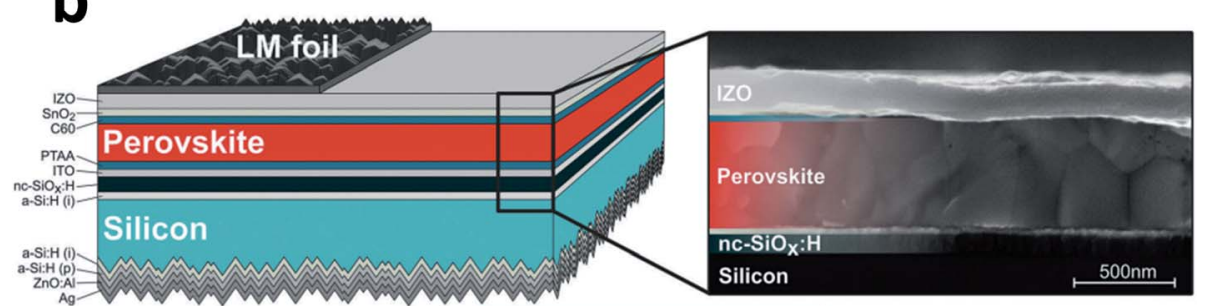

Jošt et al, PCE $25.5 \%$

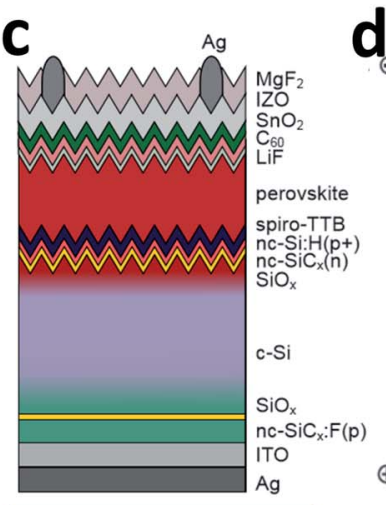

Nogay et al, PCE $25.1 \%$
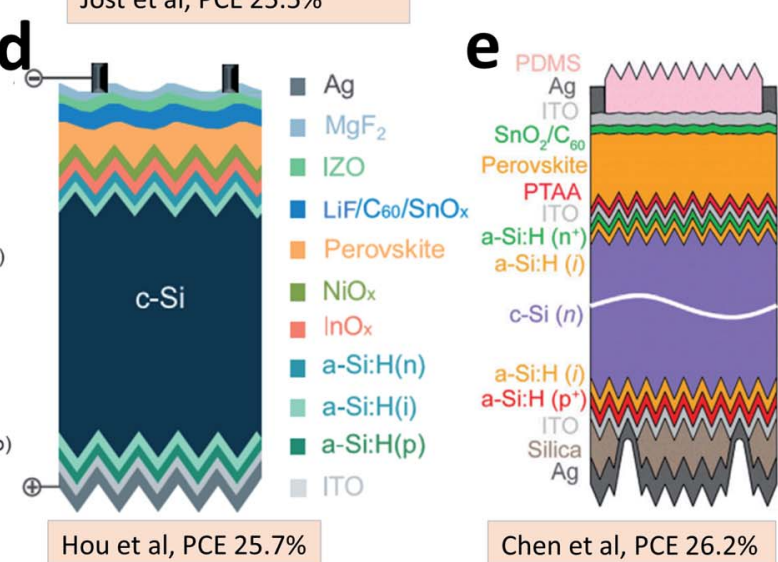

Chen et al, PCE 26.2\%

Fig. 5 (a) Schematics stack of perovskite/Si tandem solar cell with novel self-assembled monolayers as hole transport layers and SEM image of device, ${ }^{53}$ reproduced with permission. Copyright 2020, American Association for the Advancement of Science. (b) Schematics illustration of perovskite/rear texture silicon tandem solar cell, SEM cross section image of the top cell, 42 reproduced with permission. Copyright 2018 , Royal Society of Chemistry. (c) Schematic of the perovskite/front texture p-type c-Si tandem solar cell, ${ }^{78}$ reproduced with permission. Copyright 2019 , American Chemical Society. (d) Schematic of perovskite-textured silicon tandem architecture, ${ }^{64}$ reproduced with permission. Copyright 2020 ,

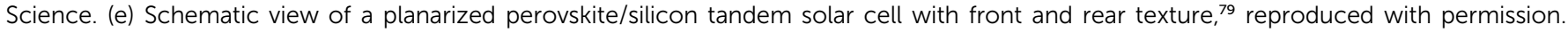
Copyright 2020, Elsevier.

stability ${ }^{66}$ (see line 18 in Table 1). The device retained $20.7 \%$ PCE after 1000 hours of continuous illumination. ${ }^{66}$ In 2020, Xu et al. reported a 2-T monolithic Si/perovskite tandems solar cell with $27 \%$ PCE. ${ }^{75}$ Triple-halide alloys (chlorine, bromine, iodine) were used to tune the band gap of perovskite top cells. The semitransparent top cells exhibit good stability for the standards of perovskite photovoltaics. After 1000 hours operation at maximum power point, the PCE has degraded by less than $4 \%$. The reported results make clear that ion engineering offers an effective approach to achieve high performance tandems solar cell.

\subsection{Optimization of Si-based bottom cells}

At the interface between the perovskite top cell and the Si bottom cell, cell design requires a tunnel contact for electrical functionality. From an optical point of view, at this interface substantial refractive index differences occur. Silicon has substantially higher refractive indices (3.5 to 4 in the relevant wavelength range) than either the perovskite absorber or the typically used metal oxide or organic contact and transport layers. Hence, the interface between the two cells might cause significant reflection losses. In order to reduce reflection, reduce parasitic absorption, and enhance light trapping in the cell, light management is essential to improve the photocurrent absorption of silicon bottom cells. The common light management methods include the introduction of optical interlayers and textured interfaces into the device. The first monolithic perovskite/silicon tandem was made with a diffused silicon $\mathrm{p}-\mathrm{n}$ junction, a tunnel junction made of $\mathrm{n}^{++}$hydrogenated amorphous silicon $(\mathrm{a}-\mathrm{Si}: \mathrm{H}), \mathrm{TiO}_{2}$ electron transport layer, methylammonium lead iodide absorber, and SpiroOMeTAD hole transport layer. ${ }^{76}$ The PCE was only $13.7 \%$ due to low matched current density which was limited by excessive parasitic absorption of light in the hole transport layer. It is difficult to texture the contact surface with the perovskite solar cell, and the light trapping effect can only be achieved on the back surface. In order to solve this problem, Bush et al. adopted the local back contact technology that gradually entered the mainstream on crystalline silicon and use silicon nanoparticles to achieve the isolation of back silver and ITO $^{56}$ (see line 3 in Table 1). The reflector comprising a silicon nanoparticle (Si NP)/ silver stack show an over $99 \%$ rear internal reflectance. $300 \mathrm{~nm}$ thick Si NP was deposited on textured ITO film between the wafer and metal reflector to increase the rear internal reflectance by reducing the light that reaches the loss metal layer. The tandem device obtained $23.6 \%$ efficiency with no hysteresis, the stable maximum power was maintained for more than half an hour under illumination. $\mathrm{Si}_{x} \mathrm{~N}_{y}$ is also used on a textured surface to balance low broadband reflection and absorption losses. It is reported that $\mathrm{Al}_{2} \mathrm{O}_{3} / \mathrm{Si}_{x} \mathrm{~N}_{y}$ and $\mathrm{Si}_{x} \mathrm{~N}_{y}$ films were used 
to passivate the front and rear surface of c-Si, respectively. ${ }^{55} \mathrm{On}$ the front side, a specially tuned $\mathrm{Si}_{x} \mathrm{~N}_{y}$ film is used to better match the refractive index of the c-Si wafer and suppress the reflection loss of the bottom cell. On the rear side of the textured c-Si cell, low refractive index $\operatorname{Si}_{x} \mathrm{~N}_{y}$ is added to enhance the light trapping capability. As a result, after 1200 seconds illumination, the device achieved a PCE of $22.5 \%$ at steady state (see line 2 in Table 1). Besides, $110 \mathrm{~nm}$ thick nanocrystalline silicon oxide (nc-SiO ${ }_{x}: \mathrm{H}$ ) with a refractive index of 2.6 was used as optical interlayer between both subcells to reduce infrared reflection losses. ${ }^{43}$ The incorporation of $\mathrm{nc}^{-\mathrm{SiO}_{x}}: \mathrm{H}$ interlayer in tandem cells cause a significantly increased of bottom cell current density. After optimization, the short circuit current density exceeds $19 \mathrm{~mA} \mathrm{~cm}^{-2}$ and the stabilized certified efficiency reached $25.2 \%$ (see line 6 in Table 1 ). In addition to Si NP, $\mathrm{Si}_{x} \mathrm{~N}_{y}$ and $\mathrm{nc}_{-} \mathrm{SiO}_{x}: \mathrm{H}$, wide band gap $\mathrm{SiC}$ were reported in solar cells to ensure high optical transparency and enable good passivation. ${ }^{77}$

In recent years, textured silicon wafers were also utilized for light management and integrating perovskite onto textured silicon which provide effective approach to 30\% PCE tandem solar cells. Jošt et al. combined experimental works with optical simulations to analyze the tandems with texture at different interfaces. ${ }^{42}$ Silicon with a planar front side and textured back side was utilized as bottom cell as shown in Fig. 5b. As a result, a PCE of $25.5 \%$ was achieved for the 2-T triple cation perovskite $\mathrm{Cs}_{0.05}\left(\mathrm{MA}_{0.17} \mathrm{FA}_{0.83}\right) \mathrm{Pb}_{1.1}\left(\mathrm{I}_{0.83} \mathrm{Br}_{0.17}\right)_{3} / \mathrm{Si}$ tandem solar cell (see line 7 in Table 1). The optical simulation results show the performance of front-side textured devices is significantly better than front-side planar device. The validated model result indicates the PCE potential of a best performing double-side textured device will be $32.5 \%$ for a perovskite with $1.66 \mathrm{eV}$ bandgap. At the same time, p-type c-Si wafer with front texture used as bottom solar cell was reported by Nogay et al. ${ }^{78}$ In these perovskite tandem solar cells based on p-type c-Si, p-type $\mathrm{SiC}_{x}$ used on the rear side to form the hole contact and n-type $\mathrm{SiC}_{x}$ was used on the on front side to provide electron selectivity. In order to obtain low interface recombination, the p-type c-Si wafer is capped on both sides by an approximately $1.2 \mathrm{~nm}$ thick $\mathrm{SiO}_{2}$ layer. The structure of the device was shown in Fig. 5c. As a result, perovskite/p-type c-Si tandem solar cell demonstrated a steady-state power conversion efficiency of $25.1 \%$. Fabricating tandem solar cells on double-side textured cSi cells is a promising method to achieve high PCE, by exploiting the increased infrared absorption by light trapping and reduced front surface reflection. For the first time a double-side textured silicon bottom cell with a $25.2 \%$ certified PCE was reported by Sahli et al. ${ }^{43}$ The perovskite top cell was processed directly on the textured bottom cell. However, depositing perovskite layer on textured silicon with a typical pyramid height of several $\mu \mathrm{m}$ is still a huge challenge.

An alternative is the use of much smaller pyramids that are completely covered by the perovskite solar cell which then has to have absorber layer thicknesses of around $1 \mu \mathrm{m}$. One of the first successful implementations of this approach was presented by Hou et $a .^{64}$ and is shown in Fig. 5d. A power conversion efficiency of $25.7 \%$ was certified by combining solution-processed micrometer-thick perovskite top cells with fully textured silicon heterojunction bottom cells (see line 16 in Table 1). The devices present stable performance after 400 hours at $85{ }^{\circ} \mathrm{C}$. Another double-side textured tandem device was introduced by the group of Jinsong Huang (see Chen et al. in Fig. 5e). ${ }^{79}$ Silicon wafers was textured with pyramids less than 1 $\mu \mathrm{m}$ in height in potassium-hydroxide-based solutions. These pyramids are rough enough to scatter light, but smooth enough to solution process a perovskite layer. Here, a dense perovskite absorber film on textured silicon is fabricated by $\mathrm{N}_{2}$-assisted blade coating at a speed of $1.5 \mathrm{~m} \mathrm{~min}^{-1}$, followed by thermal annealing for perovskite crystallization. Textured lightscattering layer on the top of the tandem cell is employed to reduce the reflectance of front-surface. As a result, perovskite/ double-side textured silicon tandem cell achieved a PCE of $26.2 \%$. Fig. 6 presents schematic illustrations of perovskite/ silicon tandem solar cells by implementing textures at different interfaces and the $J-V$ parameters from Table 1 . The simplest device design without any textured interfaces is shown in Fig. 6a. Fig. $6 \mathrm{~b}$ and $\mathrm{c}$ represent perovskite/silicon tandem solar cells utilizing a rear-side textured Si subcell and doubleside textured Si subcell, respectively. The back-side texture enhances photocurrent generation in the near infrared wavelength region. The front-side textured reduces reflection and enables enhanced light trapping by backscattering the upward propagating light. ${ }^{64} J-V$ parameters in Fig. 6 show textured light management enables significant gains in photocurrents. Optical interlayers and textured interfaces are effective methods to reduce the optical losses in tandem device.

\section{Si-based perovskite photodetectors}

Photodetectors have important applications in military, aerospace, communications, and biological imaging. ${ }^{80-83}$ A photodetector is a device for detecting and measuring a photon flux via the photoelectric effect, which generally manifests as a photocurrent. In a photodetector, the semiconductor material is essential for absorbing incident photons and generating electron-hole pairs under photoexcitation. Then the electrons and holes are separated by a built-in or applied electric field to produce an electric current. One of the most common photodetector types is a photoconductor with a metal-semiconductor-metal architecture forming the source and drain electrodes. Photo field-effect transistors (photo-FET) based photodetectors are similar to photoconductors with a third contact gate electrode. The most important parameters to evaluate the performance of photodetectors include the response time (rise time and decay time), the responsivity $(R, \mathrm{~A}$ $\mathrm{W}^{-1}$ ), the detectivity ( $D^{*}$, Jones), the external quantum efficiency (EQE, \%), the photoconductive gain $(G)$ and the photocurrent/dark-current ratio. Inorganic semiconductors such as Si and GaN are widely used for photodetectors especially for UV-light metal-semiconductor-metal architecture forming the source and drain electrodes. However, the fabrication processes are complex and expensive, and photodetectors with high driving voltage are an obstacle for some applications. In the past few years, solution processable materials such as halide 

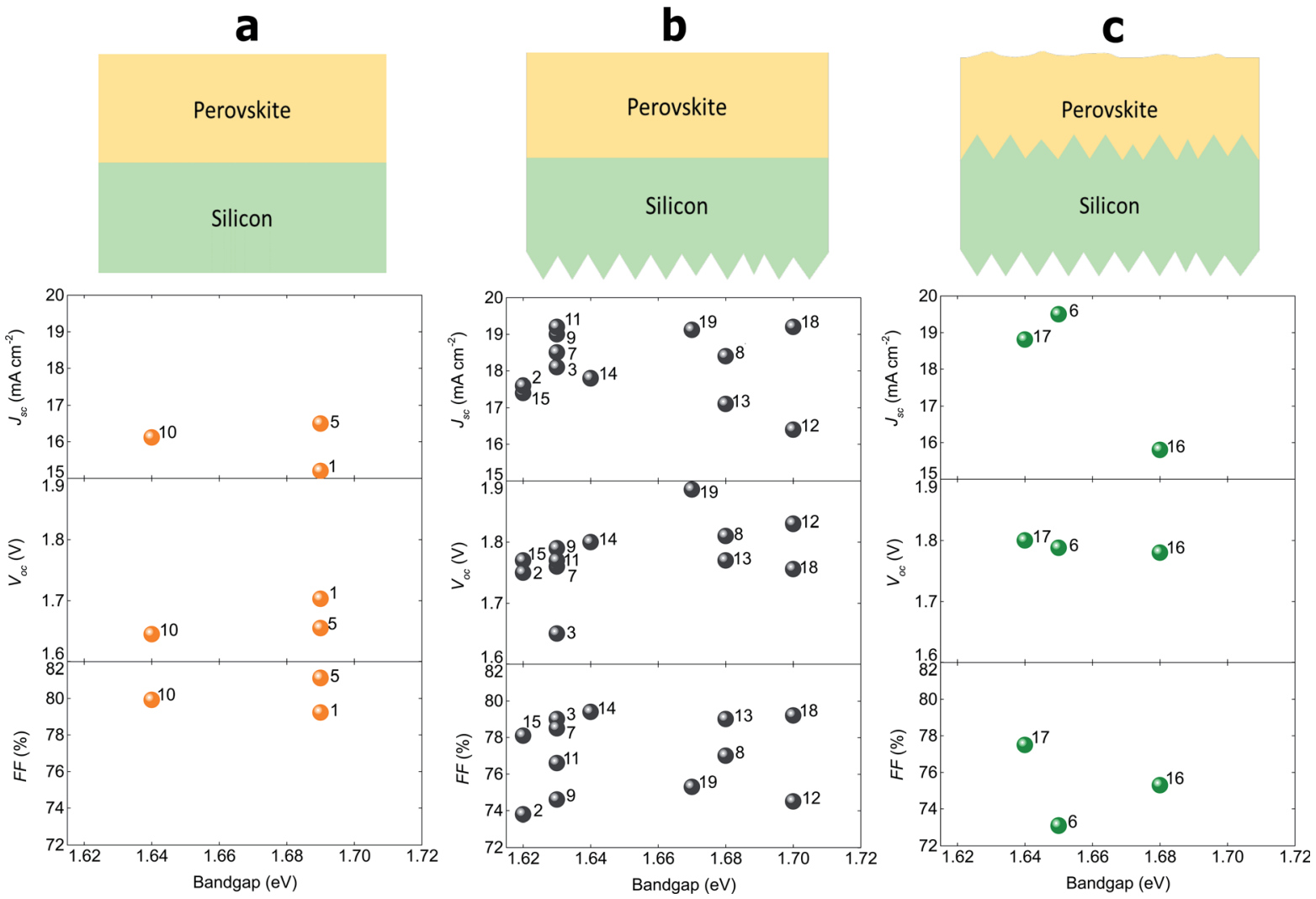

Fig. 6 Schematic illustration of perovskite/silicon tandem solar cell with different bottom cell and summary of $J-V$ parameters. The numbers in the figure are consistent with those in Table 1. (a) Perovskite/silicon tandem solar cell with flat Si subcell. (b) Perovskite/silicon tandem solar cell with rear texture Si subcell. (c) Perovskite/silicon tandem solar cell with a double textured Si subcell.

perovskite have shown the potential for preparing photodetectors with a simple process, low cost and high responsivity. The prepared photodetectors based on polycrystalline perovskite films typically exhibit performance degradation which can be avoided $e . g$. by using low-dimensional halide perovskites with high crystallinity. ${ }^{84-87}$ In order to further increase the responsivity, low-dimensional perovskites have been combined with other low-dimensional materials such as graphene, tungsten disulfide and molybdenum disulfide to fabricate photodetectors with unique structures and photoelectric properties. Table 2 summarizes the performance parameters of low-dimensional perovskite photodetectors based on $\mathrm{SiO}_{2} / \mathrm{Si}$. Fig. 7a shows the responsivity and response time of various perovskite photodetector (including nanosheets (NSs)/nanoplates, nanowires (NWs)/nanorods (NRs), quantum dots (QDs)/nanocrystals (NCs) and microparticles). A structure-responsivity relationship of low dimensional perovskite photodetector was present. Fig. 7b plots the detectivity versus light source wavelength for reported low dimensional perovskite photodetectors. The wavelength of light sources ranges from $400 \mathrm{~nm}$ to $650 \mathrm{~nm}$. The highest values of responsivities and detectivities are $8.2 \times 10^{8} \mathrm{~A} \mathrm{~W}^{-1}$ and $2.4 \times$ $10^{16}$ Jones, respectively (Fig. 7a and b), which were achieved by $\mathrm{CsPbBr}_{3-x} \mathrm{I}_{x}$ nanocrystal photodetectors. In this section, we present the recent developments of Si-based low dimensional halide perovskite photodetectors.

\subsection{Perovskite nanosheets/Si photodetectors}

2D perovskites have a unique planar geometry, which is advantageous for fabricating thin-film devices. A rich engineering of $2 \mathrm{D}$ perovskite has been demonstrated by many different methods, including micromechanical exfoliation, ${ }^{108}$ chemical vapor deposition ${ }^{109-111}$ and one-step solution selfassembly. ${ }^{112}$ The uncontrolled precipitation of the perovskite will produce large morphological variations, which would be the major barriers for practical applications. Liu et al. ${ }^{84}$ reported $2 \mathrm{D} \mathrm{CH}_{3} \mathrm{NH}_{3} \mathrm{PbX}_{3}$ perovskite as thin as a single unit cell by using a combined solution process and vapor-phase conversion method (see Fig. 8a). The 2D $\mathrm{CH}_{3} \mathrm{NH}_{3} \mathrm{PbI}_{3}$ nanosheets with different thickness all show high quantum efficiency in terms of photoluminescence (PL) yield but different PL peak positions. Liu et al. ${ }^{84}$ prepared phototransistors based on $\mathrm{CH}_{3} \mathrm{NH}_{3} \mathrm{PbI}_{3}$ nanosheets on $\mathrm{SiO}_{2} / \mathrm{Si}$ substrate (see Fig. $8 \mathrm{~b}$ ). In the device fabrication process, a patterned $\mathrm{Si}_{3} \mathrm{~N}_{4}$ shadow mask was used to prevent doping while $\mathrm{Si}$ is used as gate electrode, and $\mathrm{Au}$ was used as source and drain electrode. As a result, the $2 \mathrm{D} \mathrm{CH}_{3}$ $\mathrm{NH}_{3} \mathrm{PbI}_{3}$ nanosheets photodetector showing responsivity of 22 $\mathrm{A} \mathrm{W}^{-1}$ (see Fig. 8c), the rise time is shorter than 20 milliseconds $(\mathrm{ms})$ and the decay time is shorter than $40 \mathrm{~ms}$ (see line 1 in Table 2). Parveen et al. ${ }^{107}$ also achieved highly tuneable thickness and optical properties of the organic-inorganic halide perovskite by using a short-term solvothermal reaction method 


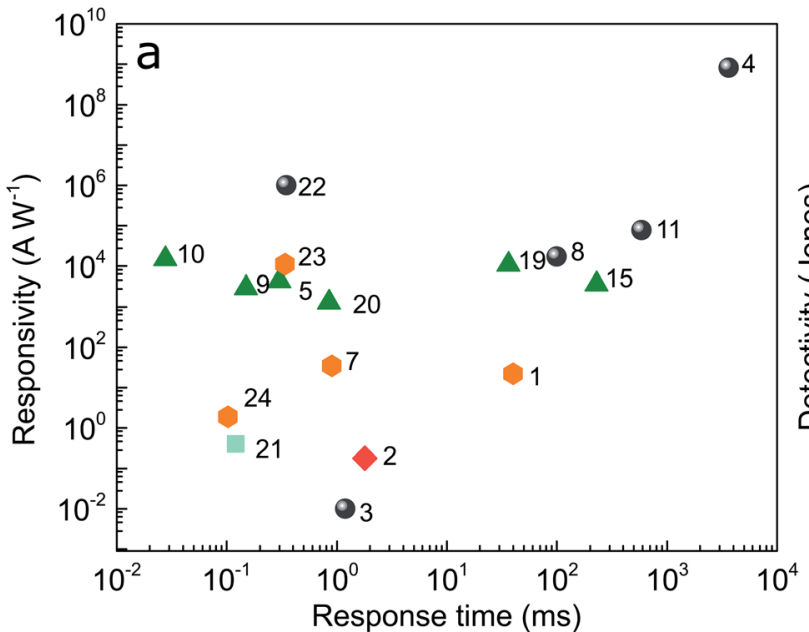

Nanosheets/Nanoplates Microparticles

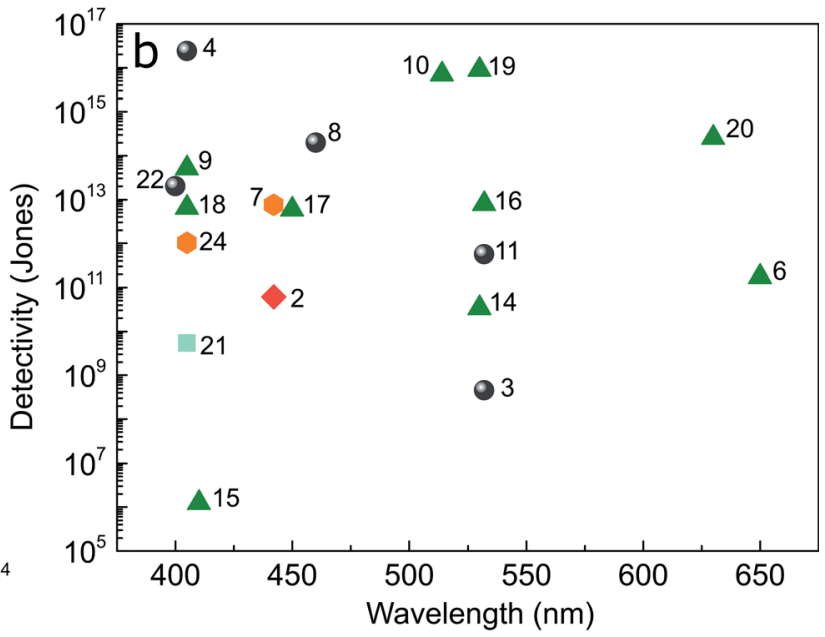

Nanocrystals/Quantum dots Films+Quantum dots

Fig. 7 (a) Various perovskite photodetector technologies plotted against their corresponding responsivity and time response. (b) Detectivity of Low dimensional perovskite photodetector as a function of light source wavelength. The numbers are corresponding to those in Table 2.

and controlling growth temperature (see Fig. 8d). The fabricated 2D perovskite nanosheets photodetector device based on $\mathrm{Si}$ / $\mathrm{SiO}_{2}$ substrate shows good stability, fast response time (rise time $24 \mu \mathrm{s} /$ fall time $103 \mu \mathrm{s}$ ) and a responsivity of $\approx 1.93 \mathrm{~A} \mathrm{~W}^{-1}$ (see Fig. 8e, f and line 24 in Table 2). Pan and co-authors ${ }^{\mathbf{1 0 6}}$ developed a fully vapor-phase method to grow highly crystalline and thickness-tuneable $\left(\mathrm{CH}_{3} \mathrm{NH}_{3}\right)_{n+1} \mathrm{~Pb}_{n} \mathrm{I}_{3 n+1}$ layers on top of $\mathrm{WS}_{2}$ monolayer (see Fig. 8g). The schematic image of perovskite/ $\mathrm{WS}_{2}$ heterostructures field-effect transistors is shown in Fig. 8h. The $\left(\mathrm{CH}_{3} \mathrm{NH}_{3}\right)_{n+1} \mathrm{~Pb}_{n} \mathrm{I}_{3 n+1} / \mathrm{WS}_{2}$ heterostructure photodetectors exhibit a photoresponsivity of $1.1 \times 10^{4} \mathrm{~A} \mathrm{~W}^{-1}$ (see Fig. 8i, line 23 in Table 2). Gao et al. ${ }^{113}$ demonstrated the synthesis of $2 \mathrm{D}$ halide perovskite lateral heterostructures via a solution-phase sequential growth method. Concentric square/rectangular 2D lateral heterostructures can be formed directly on the $\mathrm{SiO}_{2} / \mathrm{Si}$ substrate. The obtained epitaxial heterostructures, multiheterostructures and superlattices present highly stable and tuneable electronic properties. These findings open up the possibility of further exploring $2 \mathrm{D}$ halide perovskite lateral heterostructures' optoelectronic properties and their applications in optoelectronic devices and integrated circuits.

\subsection{Perovskite nanowires/Si photodetectors}

1D nanowire semiconductors have great potential in future electronic circuits and optical chips due to their high crystallinity, ${ }^{114}$ large surface-to-volume ratio, ${ }^{115}$ and chip level polarization sensitivity. ${ }^{\mathbf{1 1 6 , 1 1 7}}$ The synthesis methods of nanowires include solution-phase ${ }^{118,119}$ and vapor-phase ${ }^{120,121}$ processes. For the vapor-phase method, $\mathrm{SiO}_{2} / \mathrm{Si}$, mica and sapphire are usually used as growth substrate to promote perovskite NWs growth. $\mathrm{SiO}_{2} / \mathrm{Si}$ can also be used as the NWs growth channel combined with photoresist and photolithography technology to achieve directional growth of perovskite nanowires. Photodetectors based on 1D halide perovskites have been reported and made great progress with respect to responsivity and detectivity. Deng et al. obtained single-crystalline $\mathrm{MAPbI}_{3}$ NWs with smooth surface by fluid-guided antisolvent vapor-assisted

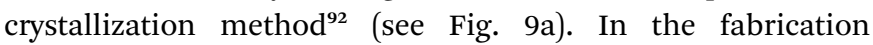
process of nanowires, a $\mathrm{SiO}_{2} / \mathrm{Si}$ substrate with periodically aligned SU-8 photoresist stripes served as a template for the subsequently aligned growth of perovskite NWs arrays. The schematic and the performance metrics responsivity and photoconductive gain of $\mathrm{MAPbI}_{3} \mathrm{NWs}$ photodetector using an $\mathrm{SiO}_{2} / \mathrm{Si}$ substrate are shown in Fig. 9b. The photodetector exhibits a broad photo-response range from 370 to $780 \mathrm{~nm}$ and high light sensitivity with maximum spectral responsivity of approximate $1.25 \times 10^{4} \mathrm{~A} \mathrm{~W}^{-1}$ (see Fig. 9c and line 6 in Table 2). Stability is one of the key challenges for the technology of perovskite device. In order to achieve stable perovskite devices, all inorganic perovskite-nanowires arrays were also utilized to fabricate photodetectors (see line 20 in Table 2). ${ }^{103}$ Chen et al. fabricated $\alpha$-CsPbI $\mathrm{Pan}_{3}$ nawires by employing an asymmetricwettability topographical template, and prepared photoconductor-type photodetectors on silicon ${ }^{\mathbf{1 0 3}}$ (see Fig. 9d and e). The stable $\alpha-\mathrm{CsPbI}_{3}$ nanowire array based photodetectors present responsivity of $1.294 \times 10^{3} \mathrm{~A} \mathrm{~W}^{-1}$ responsivity (see Fig. 9f), $2.6 \times 10^{14}$ Jones detectivity and long stability (see line 20 in Table 2). In addition to $\mathrm{CsPbI}_{3}$ nanowires, $1 \mathrm{D}$ all inorganic $\mathrm{CsPbI}_{3}$ nanorods-based photodetectors have also been reported by Yang et al. The single crystalline $\mathrm{CsPbI}_{3}$ nanorods with high quality were synthesized with a high yield via a solution process (see Fig. $9 \mathrm{~g}$ and $\mathrm{h}$ ). The inorganic perovskite-nanorods photodetector exhibited a responsivity of $2.92 \times 10^{3} \mathrm{~A} \mathrm{~W}^{-1}$ (see Fig. 9i) and $0.9 \times 10^{6} \%$ EQE with $2 \mathrm{~V}$ bias voltage and $405 \mathrm{~nm}$ light $^{95}$ (see line 9 in Table 2). More importantly, the $\mathrm{CsPbI}_{3}$ nanorod photodetectors showed high stability when kept under ambient conditions, ${ }^{95}$ which are promising to realize efficient practical application of optoelectronic devices. 


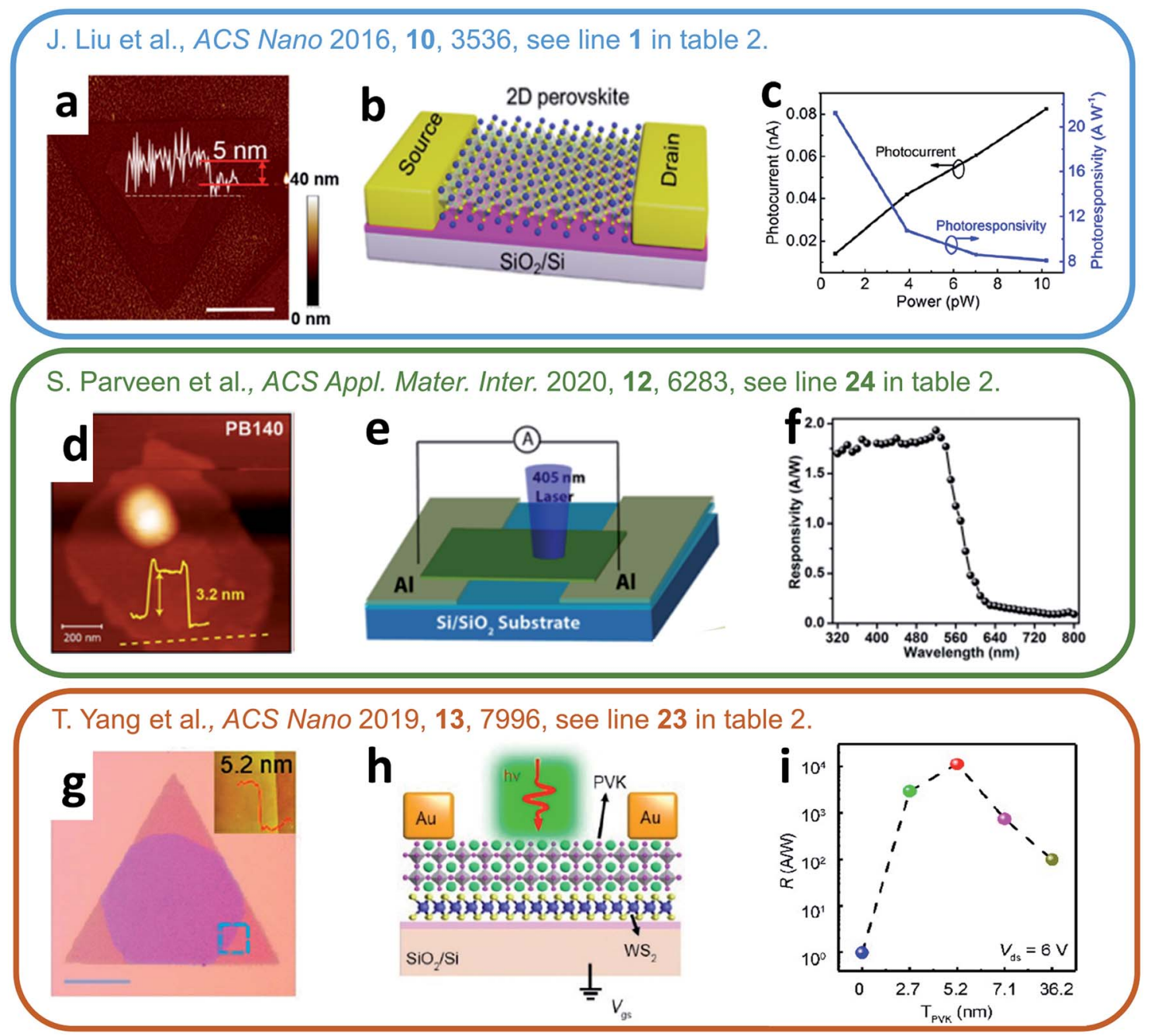

Fig. 8 Perovskite nanosheets/Si photodetectors structures and performance. $(a, d, g)$ AFM images and line scan profiles of perovskite nanosheets, (a) $\mathrm{CH}_{3} \mathrm{NH}_{3} \mathrm{Pbl}_{3}$ nanosheet, (d) $\mathrm{CH}_{3} \mathrm{NH}_{3} \mathrm{PbBr}_{2}$ nanosheet, (g) $\left(\mathrm{CH}_{3} \mathrm{NH}_{3}\right)_{n+1} \mathrm{~Pb}_{n} \mathrm{I}_{3 n+1}$ nanosheet. (b, e, h) Schematic images of photodetectors based on 2D perovskite nanosheets. (c, f, i) Photodetector responsivity ( $a, b, c)$ Reproduced with permission ${ }^{84}$ (see line 1 in Table 2 ). Copyright 2016, American Chemical Society. (d, e, f) Reproduced with permission ${ }^{107}$ (see line 24 in Table 2). Copyright 2020, American Chemical Society. (g, h, i) Reproduced with permission ${ }^{106}$ (see line 23 in Table 2). Copyright 2019, American Chemical Society.

\subsection{Perovskite quantum dots/Si photodetectors}

Inorganic perovskites QDs or NCs have emerged as a new class of photoelectronic materials owing to their relatively high stability ascompared to organic-inorganic perovskites, cost effectiveness, ${ }^{122}$ over $90 \%$ photoluminescence quantum yield in solution, ${ }^{\mathbf{1 2 3}}$ tuneable emission wavelengths and absorption onsets. ${ }^{124}$ All-inorganic $\mathrm{CsPbI}_{3}$ nanocrystals NCs were first employed in photodetectors by Ramasamy et al. in $2016 .{ }^{\mathbf{1 2 5}}$ The

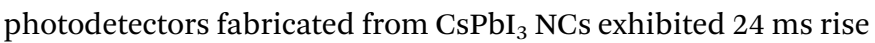
time and $29 \mathrm{~ms}$ decay time. However, the photoresponsivity of photodetectors is limited by the low charge transport efficiency of the inorganic QDs layers. ${ }^{94}$ Chen et al. combined $\mathrm{CsPbBr}_{3}$ QDs with organic semiconductors (dinaphtho[2,3-b:2',3'-f] thieno[3,2-b]thiophen (DNTT)) to fabricate heterostructure photodetectors to improve the transportation of the photoexcited charges (see Fig. 10a and b). The devices showed a photoresponsivity of $\approx 1.7 \times 10^{4} \mathrm{~A} \mathrm{~W}^{-1}$, and a detectivity of $\approx 2.0 \times 10^{14}$ Jones (see Fig. $10 \mathrm{c}$ and line 8 in Table 2). Wu et al. integrated $\mathrm{CsPbI}_{3-x} \mathrm{Br}_{x}$ QDs with monolayer $\mathrm{MoS}_{2}$ for low-cost and high performance heterostructure photodetectors. ${ }^{97}$ The $\mathrm{CsPbI}_{3-x} \mathrm{Br}_{x}$ QDs have a typical cubic shape with an average diameter of $15 \mathrm{~nm}$ (see Fig. 10d). The monolayer $\mathrm{MoS}_{2}$ used as the channel of phototransistor. Authors synthesized monolayer $\mathrm{MoS}_{2}$ by oxygen-assisted chemical vapor deposition. And then transferred it onto $\mathrm{SiO}_{2} / \mathrm{Si}$ substrate by a PMMA-assisted transfer method. In the mixed-dimensional hetero-structure photodetectors (see Fig. 10e), a favourable energy band alignment is conducive to interfacial photocarrier separation and efficient carrier injection into the $\mathrm{MoS}_{2}$ layer. The optimized mixed-dimensional heterostructure photodetectors exhibited a high photo-responsivity of $7.7 \times 10^{4} \mathrm{~A} \mathrm{~W}^{-1}, 5.6 \times 10^{11}$ Jones detectivity and $107 \%$ EQE (see Fig. $10 \mathrm{f}$ and line 11 in Table 2). Gong et al. reported a passivation process with a thiol on $\mathrm{CsPbCl}_{3}$ NCs to improve performance of photodetectors. ${ }^{\mathbf{1 0 5}}$ The 


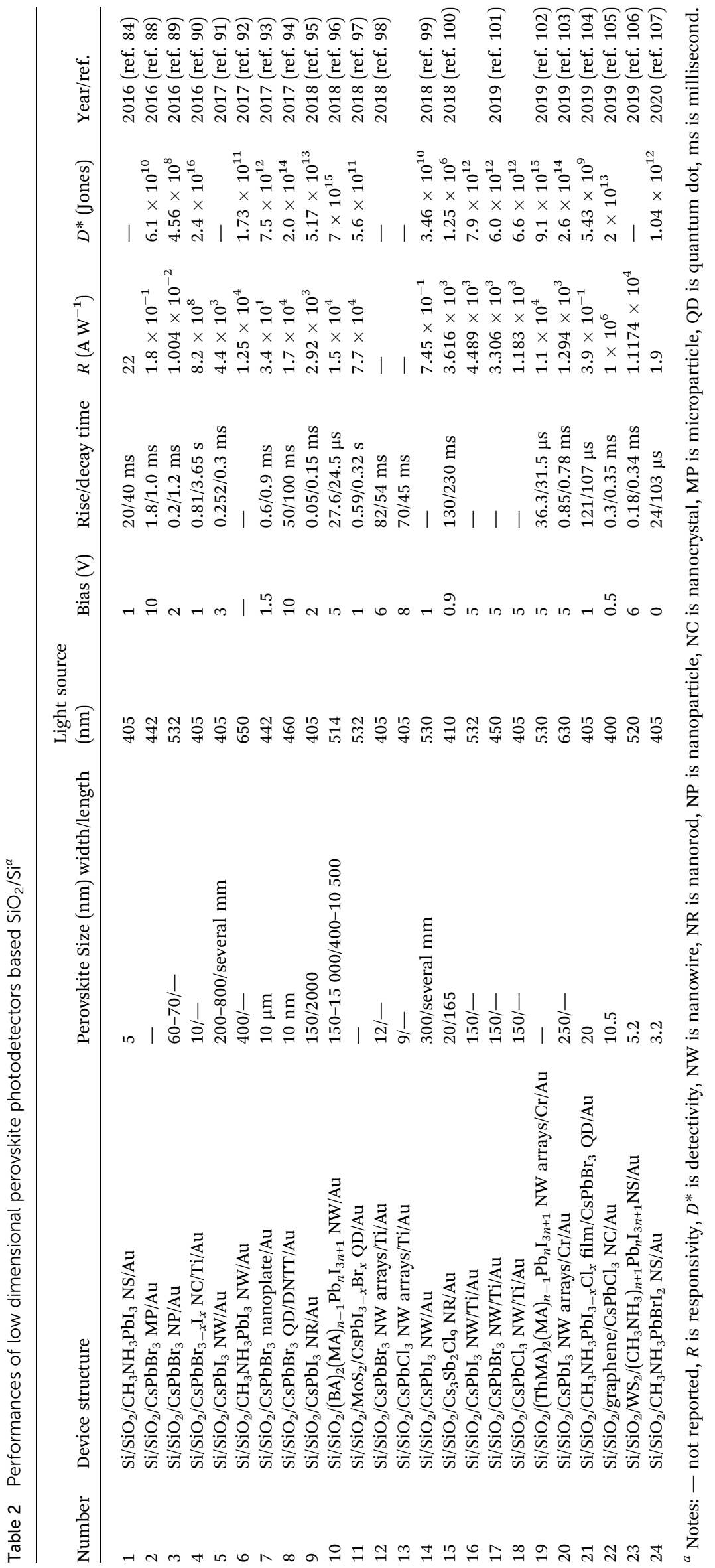


W. Deng et al., Nano Lett. 2017, 17, 2482, see line 2 in table 2.
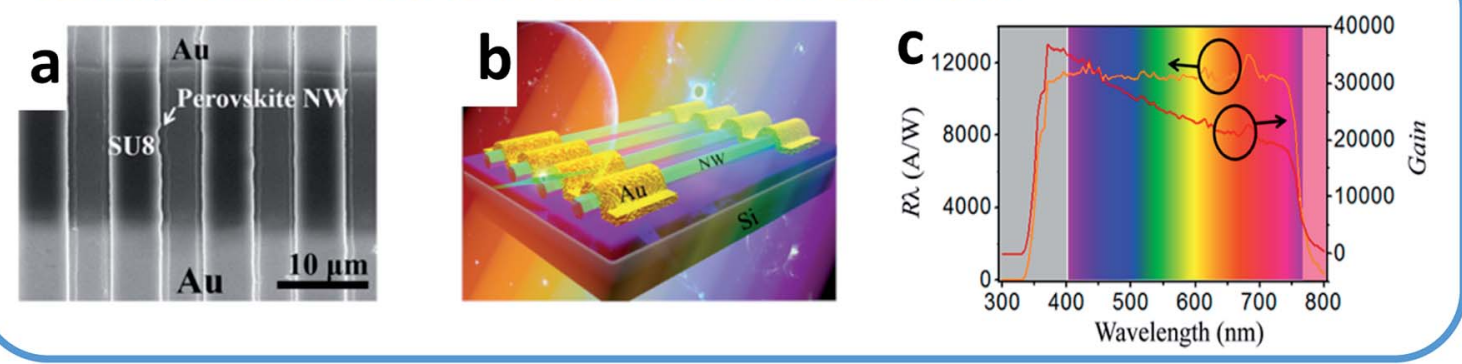

G. Chen et al., Adv. Funct. Mater. 2019, 29, 1808741, see line 20 in table 2.

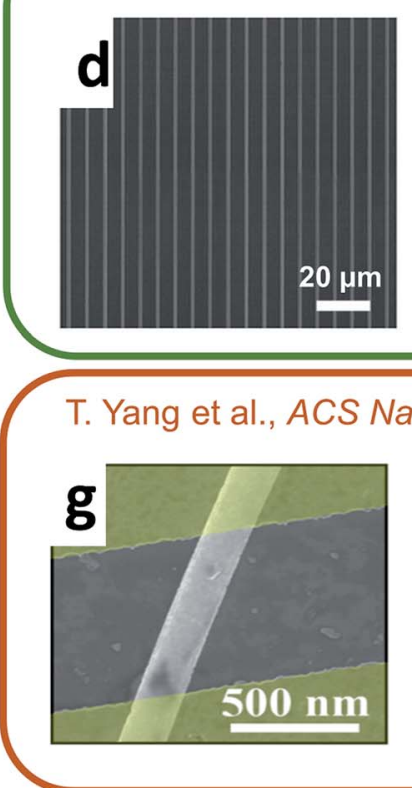

e
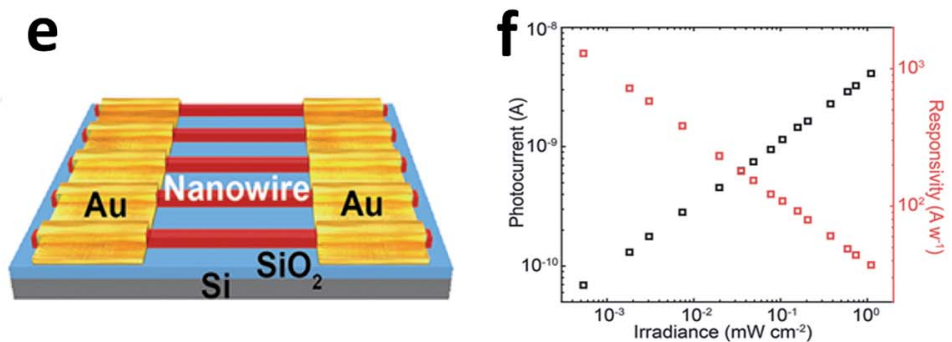

T. Yang et al., ACS Nano 2018, 12, 1611, see line 9 in table 2.
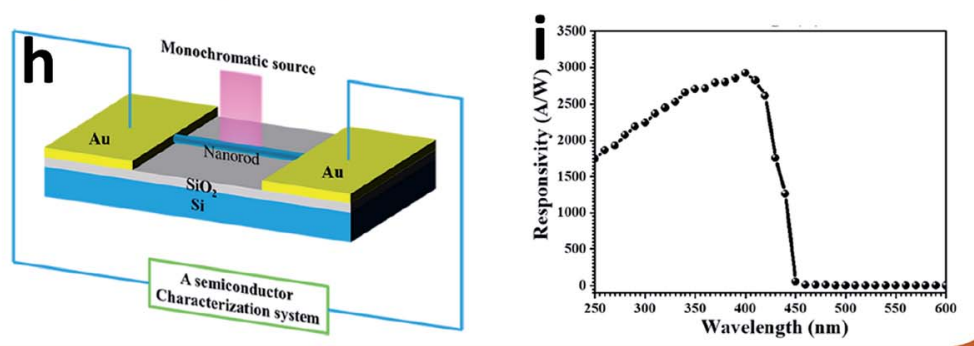

Fig. 9 Perovskite nanowires (nanorods)/Si photodetectors structures and performance. (a, d, g) SEM images of (a) $\mathrm{CH}_{3} \mathrm{NH}_{3} \mathrm{Pbl}{ }_{3}$ nanowire arrays, (d) $\alpha$-CsPbl 3 nanowire arrays, and (g) a CsPbl 3 nanorod. (b, e, h) Schematic illustrations of photodetectors based on 1D perovskite nanowires (nanorods). (c, f, i) Photodetector responsivity. (a, b, c) Reproduced with permission ${ }^{92}$ (see line 6 in Table 2). Copyright 2017, American Chemical Society. (d, e, f) Reproduced with permission ${ }^{103}$ (see line 20 in Table 2). Copyright 2019, Wiley-VCH. (g, h, i) Reproduced with permission ${ }^{95}$ (see line 9 in Table 2). Copyright 2018, American Chemical Society.

$\mathrm{CsPbl}_{3}$ NCs have an average size of $10.5 \mathrm{~nm}$ (see Fig. 10g). The surface engineering can not only facilitate high efficiency charge transfer in field-effect transistors but also minimize the charge trapping and prevent degradation of the devices based on $\mathrm{CsPbCl}_{3}$ NCs. The devices (see Fig. 10h) obtained a responsivity exceeding $10^{6} \mathrm{~A} \mathrm{~W}^{-1}$, a detectivity of $2 \times 10^{13}$ Jones and ambient stability for more than $2400 \mathrm{~h}$ (see Fig. 10i and line 22 in Table 2). Yang et al. reported photodetectors based on $\mathrm{CH}_{3}$ $\mathrm{NH}_{3} \mathrm{PbI}_{3-x} \mathrm{Cl}_{x}$ layers and $\mathrm{CsPbBr}_{3}$ QDs on a $\mathrm{SiO}_{2} /$ Si substrate. ${ }^{\mathbf{1 0 4}}$ After introducing inorganic perovskite QDs into $\mathrm{CH}_{3} \mathrm{NH}_{3}$ $\mathrm{PbI}_{3-x} \mathrm{Cl}_{x}$ photodetector, the device achieved a higher gain with a lower dark current than single $\mathrm{CH}_{3} \mathrm{NH}_{3} \mathrm{PbI}_{3-x} \mathrm{Cl}_{x}$ photodetector. The maximum responsivity of $\mathrm{CH}_{3} \mathrm{NH}_{3} \mathrm{PbI}_{3-x} \mathrm{Cl}_{x}$ perovskite- $\mathrm{CsPbBr}_{3}$ QDs hybrid photodetector is obviously larger than that of $\mathrm{CH}_{3} \mathrm{NH}_{3} \mathrm{PbI}_{3-x} \mathrm{Cl}_{x}$ perovskite photodetectors without $\mathrm{CsPbBr}_{3}$ QDs. The enhanced responsivity is attributed to the ability of the $\mathrm{CsPbBr}_{3}$ QDs to achieve efficient light absorption and carrier injection into the perovskite layer. The devices exhibited $\approx 121 \mu$ s rise time and $\approx 107 \mu$ s fall times (see line 21 in Table 2).

Due to the mature technology of Si-based devices, researchers have also combined silicon directly with perovskite QDs to prepare heterojunction photodetectors. The interface of the perovskite-Si heterojunction can promote the separation and transmission of photo-generated carriers, which can not only broaden the light detection range, but also increase the light response rate. ${ }^{\mathbf{1 2 6}}$ The perovskite quantum dots are evenly distributed on the surface of the three-dimensional framework of the Si nanowire radial junction. Perovskite quantum dots on the surface of the device absorb high-energy photons, and then convert them into lower-energy photons that are absorbed in the Si-based $\mathrm{p}-\mathrm{n}$ junction region to realize sensitive photodetection. The Si nanowire radial junction (with $80 \mathrm{~nm}$ i-layer) can respond to the visible $512 \mathrm{~nm}$ wavelength modulation.

After spin-coating inorganic perovskite $\mathrm{CsPbBr}_{3}$ QDs on the surface of the Si nanowire, the perovskite QDs radial junction 


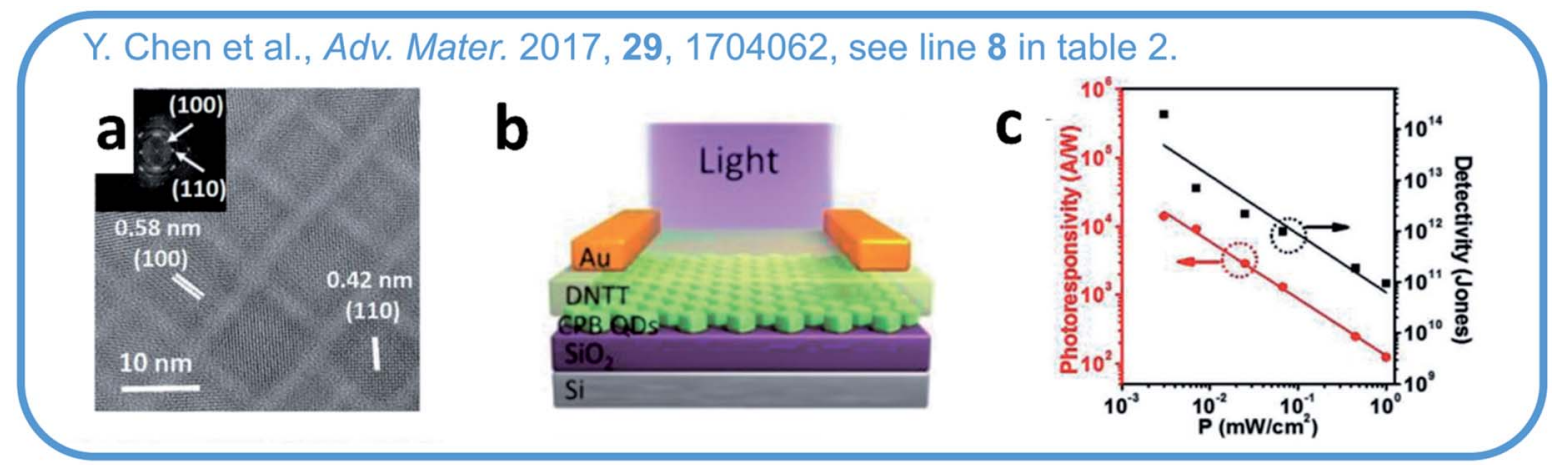

H. Wu et al., Adv. Sci. 2018, 5, 1801219, see line 11 in table 2.
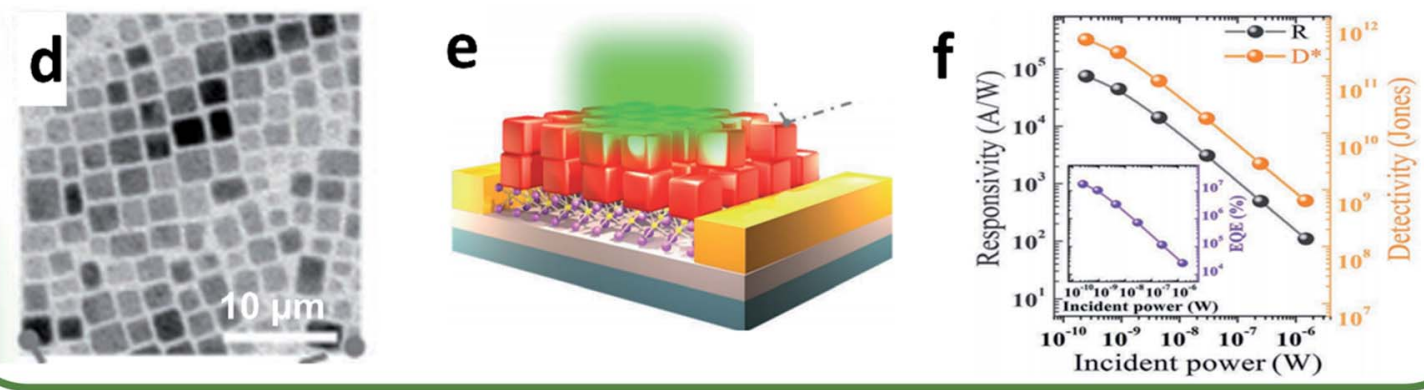

M. Gong et al., ACS Nano 2019, 13, 1772, see line 22 in table 2.
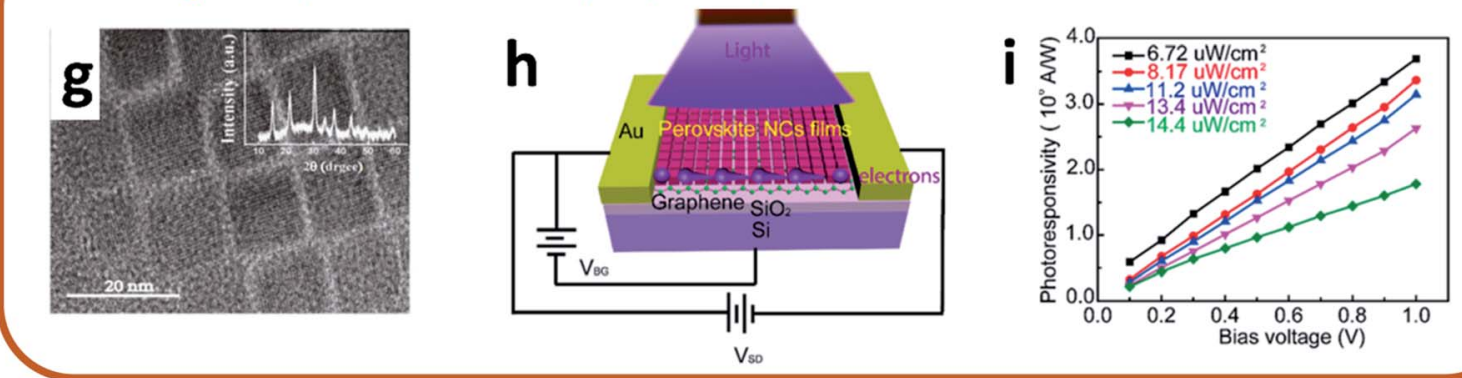

Fig. 10 Perovskite QDs (NCs)/Si photodetectors structures and performance. (a, d, g) TEM images of perovskite QDs (nanocrystal), (a) $\mathrm{CsPb}_{3-x} \mathrm{Br}_{x} \mathrm{QDs}$, (d) $\mathrm{CsPbCl}_{3} \mathrm{NCs}$, (g) $\mathrm{CsPbBr}_{3}$ QDs. (b, e, h) Schematic illustrations of photodetector based on perovskite QDs (nanocrystal). (c, f, i) The device performance. (a, b, c) Reproduced with permission ${ }^{94}$ (see line 8 in Table 2). Copyright 2017, Wiley-VCH. (d, e, f) Reproduced with permission ${ }^{97}$ (see line 11 in Table 2). Copyright 2018, Wiley-VCH. (g, h, i) Reproduced with permission ${ }^{105}$ (see line 22 in Table 2). Copyright 2019 , American Chemical Society.

detector can catch up the alternating stimulations up to $\approx 1$ kHz. The Si nanowire/CsPbBr 3 QDs photodetector exhibited 0.48/1.03 $\mathrm{ms}$ rise/fall time for UV wavelength detection. Combining the two materials results in a highly efficient siliconbased perovskite detector, which provides a new and effective way for photoelectric integration of portable multi-functional devices.

\section{Si-based perovskite light emitting diodes}

In general, LEDs consist of a transparent electrode (e.g., FTO, ITO), electron-transporting layer, emitter layer, holetransporting layer and back electrode. The carriers are injected through the electrode and transported efficiently to the emitter layer, following by radiative recombination and generating light emission. The generated light is transmitted through the electron-transporting layer or hole-transporting layer and the transparent electrode. For a high-performance device, the choice of emitter material and the design and selection of the interfaces are critical to suppress unwanted non-radiative recombination. Perovskites with a direct band gap have the advantages of adjustable wide spectral band gap and high luminescence quantum efficiency, and have therefore important application prospects in the field of light sources. But low stability is the biggest obstacle to perovskite's commercial application. Inorganic perovskite QDs demonstrate better thermal stability and low humidity sensitivity. They are expected to be new generation of light-emitting display materials. In 2015, Protesescu et al. reported the first successful preparation of $\mathrm{CsPbX}_{3}(\mathrm{X}=\mathrm{Cl}, \mathrm{Br}, \mathrm{I}$, and their mixtures) nanocrystals by the thermal injection method. ${ }^{127}$ In 2016, researchers have 
developed all-inorganic perovskite QDs $\left(\mathrm{CsPbX}_{3}, \mathrm{X}=\mathrm{Cl}, \mathrm{Br}, \mathrm{I}\right.$, and their mixtures) in practical applications. ${ }^{128}$ In the past few years, researchers have improved the luminous efficiency and stability of inorganic perovskite QDs LEDs through surface modification of QDs, interface modification and carrier transport layer optimization. All inorganic hole transport materials $\left(\mathrm{NiO}_{2}, \mathrm{MoO}_{3}, \mathrm{CuSCN}\right)$ and electron transport materials (ZnO, $\mathrm{TiO}_{2}$ ) were utilized in devices to overcome the emission efficiency and operational stability. ${ }^{\mathbf{8} 41}$ Impressive external quantum efficiencies (EQEs) up to $21.6 \%$ in the near-infrared (NIR) region, ${ }^{129} 21.3 \%$ in the red region, ${ }^{130} 22 \%$ in green region and $12.3 \%$ in the blue region ${ }^{\mathbf{1 3 1}}$ have been achieved.

Several groups combined perovskite emission layers with $\mathrm{Si}$ based substrates to fabricate LEDs as listed in Table 3. Liu et al. demonstrated inorganic $\mathrm{CsPbX}_{3}$ QDs/p-type Si heterojunction LEDs by using p-type crystalline $\mathrm{Si}$ as hole transport layer (Fig. 11a). ${ }^{25}$ The perovskite/Si heterojunction LEDs show strong green and red light emission (Fig. 11b and c). The full width at half maximum of emission peak is very narrow, nearly $22 \mathrm{~nm}$ and $30 \mathrm{~nm}$ for the green and red emission, respectively. The authors optimized the energy band alignment to improve the performance of Si-based perovskite LEDs. ${ }^{132}$ Fig. 11d shows the schematic and energy band diagrams of device. After optimizing the energy level, the hole injection barrier is reduced. The $\mathrm{Si} / \mathrm{CsPbI}_{3}$ QDs LEDs obtained $1.68 \mathrm{~mW} \mathrm{~cm}^{-2}$ output power density and $0.91 \%$ EQE (Fig. 11e and f).

The performance of perovskite/p-Si LEDs under different driving modes was studied in ref. 133. Compared to LEDs under direct current (DC) mode, LEDs show higher EL intensity, lower power consumption and better stability when driven in alternating current (AC) mode. ${ }^{25,133}$ Recently, Xu et al. reported nearinfrared (NIR) perovskite light-emitting diodes based on Si (see Fig. 11g). ${ }^{26}$ Choline chloride was used as passivation layer to improve the EL intensity of devices. The LEDs with $0.5 \mathrm{mg} \mathrm{ml}^{-1}$ choline chloride achieved higher EL intensity than other devices. The Si-MAPbI ${ }_{3}$ LEDs present NIR wavelength emission with $785 \mathrm{~nm}$ spectra peak and a full width at half maximum (FWHM) of $55 \mathrm{~nm}$. The performance of perovskite LEDs based on $\mathrm{Si}$ is still lower than perovskite LEDs with organic transport layers. The perovskite/Si light emitting diodes are still at an early stage of development. The large leakage current, low EQE and short lifetime are the urgent problems that need to be overcome.

\section{Si-based perovskite lasers}

Lasers occupy important position in people's lives and have been widely used in various technical and scientific fields, such as biological imaging, manufacturing, spectroscopy and optical communications. ${ }^{135}$ Halide perovskite exhibits potential applications in laser ${ }^{136-147}$ due to high luminescence quantum yield, ${ }^{148}$ tuneable emission wavelength ${ }^{11}$ and low defect state density. ${ }^{18} \mathrm{Up}$ to date, most of perovskite lasers are optically pumped. Nanostructures in optically pumped laser could not only provide optical feedback, ${ }^{\mathbf{1 4 9 , 1 5 0}}$ but also reduce the lasing threshold as well as increase the quality factor by reducing the roughness and providing better light confinement. ${ }^{23}$ Perovskite nanostructures, such as single crystalline nanowires and nanoplates, can be used as both gain media and optical microcavities, which is particularly promising for high-quality small-sized laser sources. ${ }^{151-153}$ However, it is difficult to fabricate patterned perovskites arrays directly due to the urgent challenges of the incompatibility of perovskite with the typical lithographic process. ${ }^{154}$ In contrast, the process of preparing patterned Si-based materials through photolithography or electron beam lithography is a mature technology. Patterned perovskite could be obtained by integrating halide perovskites with Si-based pre-patterned substrate. Optical resonator is the main part of laser, which has different shape and architecture. Researchers have demonstrated optically pumped lasers based on Si using various optical feedback structures such as whispering gallery cavities (WG), photonic crystal bandedge and distributed feedback gratings. ${ }^{67}$ Table 4 summarized the characteristics of Si-based perovskite lasers with different mode.

\subsection{Whispering gallery cavities mode Si-based perovskite laser}

In WG mode laser, resonators are the microstructures which can provide effective confinement for electromagnetic or acoustic waves via total internal reflection, such as microspheres, microdisks, microcylinders and microtoroids. WG mode resonators could be obtained by spin-coating, dropcasting or depositing perovskite precursor on pattern Si-based template directly and nanoimprint lithography. The sizes of patterned perovskites were controlled by the diameter of pattern substrate and the perovskites precursor concentration.

Table 3 Summary of Si-based perovskite LEDs reported in recent years ${ }^{a}$

\begin{tabular}{|c|c|c|c|c|c|c|c|c|}
\hline Number & Perovskite & Device structure & $\mathrm{EL}(\mathrm{nm})$ & FWHM (nm) & EQE $(\%)$ & Driving mode & $\begin{array}{l}\text { Max lumin. } \\
\left(\mathrm{cd} \mathrm{m}^{-2}\right)\end{array}$ & Year/ref. \\
\hline \multirow[t]{2}{*}{1} & $\mathrm{CsPbBr}_{3}$ QDs & Al/p-Si/perovskite/ZnO/ITO & 512 & 22 & - & DC & - & \multirow[t]{2}{*}{2018 (ref. 25) } \\
\hline & $\mathrm{CsPbI}_{3}$ QDs & $\mathrm{Al} / \mathrm{p}-\mathrm{Si} /$ perovskite/ZnO/ITO & 685 & 30 & - & $\mathrm{DC}, \mathrm{AC}$ & - & \\
\hline \multirow[t]{2}{*}{2} & $\mathrm{CsPbI}_{3}$ QDs & $\mathrm{Al} / \mathrm{p}-\mathrm{Si} /$ poly-TPD/perovskite/ZnO/ITO & 690 & 30 & 0.91 & DC & 665 & \multirow[t]{2}{*}{2018 (ref. 132) } \\
\hline & $\mathrm{CsPbBr}_{3}$ QDs & $\mathrm{Al} / \mathrm{p}-\mathrm{Si} / \mathrm{Au} /$ poly-TPD/perovskite/ZnO/ITO & 513 & 22 & - & DC & 403 & \\
\hline 3 & $\mathrm{CsPbI}_{3}$ QDs & $\mathrm{Al} / \mathrm{p}-\mathrm{Si} /$ poly-TPD/perovskite/ZnO/ITO & 690 & 30 & - & $\mathrm{AC}$ & 850 & 2018 (ref. 133) \\
\hline 4 & $\mathrm{CsPbBr}_{3}$ QDs & $\mathrm{Si} / \mathrm{SiO}_{2} /$ perovskite/Au & 555.8 & 12.2 & - & $\mathrm{AC}$ & - & 2018 (ref. 134) \\
\hline 5 & $\mathrm{MAPbI}_{3}$ films & $\mathrm{Al} / \mathrm{p}-\mathrm{Si} /$ poly-TPD/ChCl/perovskite/ZnO/ITO & 785 & 55 & 3.92 & DC & - & 2021 (ref. 26) \\
\hline
\end{tabular}

${ }^{a}$ Notes: - not reported, QDs is quantum dots, EL is electroluminescence, FWHM is full width at half maximum, DC is direct current, AC is alternating current. 


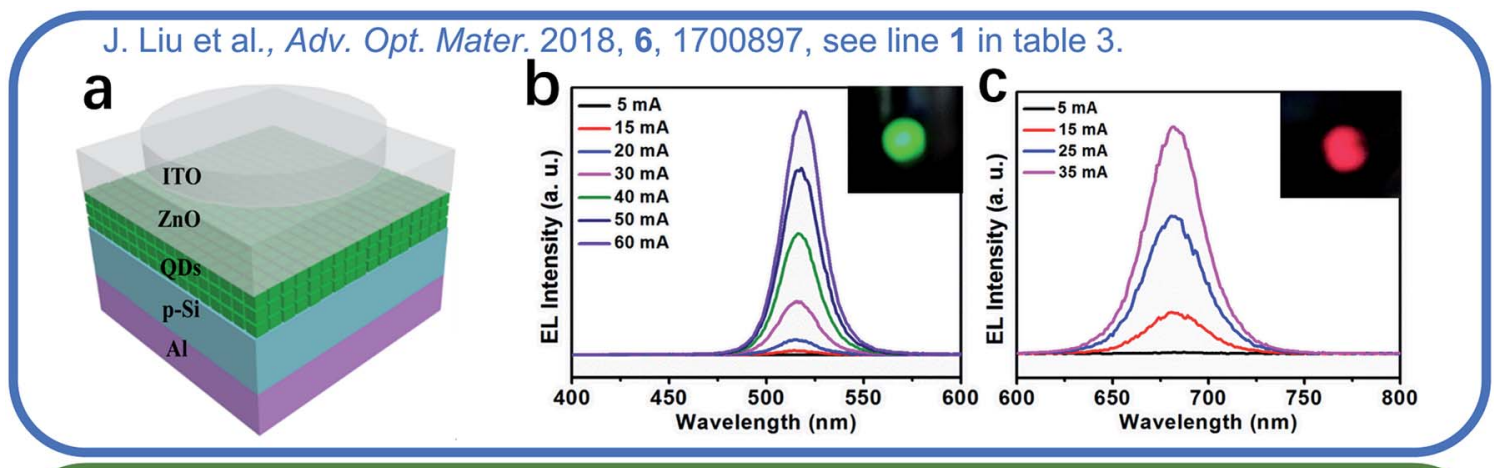

J. Liu et al., Adv. Opt. Mater. 2018, 6, 1800693, see line 2 in table 3.
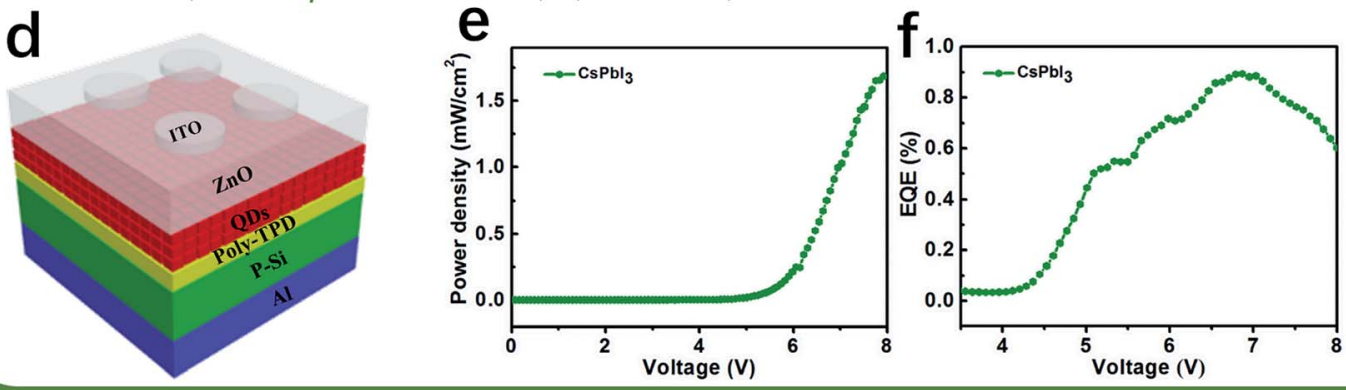

X. Xu et al., Adv. Opt. Mater. 2021, 2100636, see line 5 in table 3.
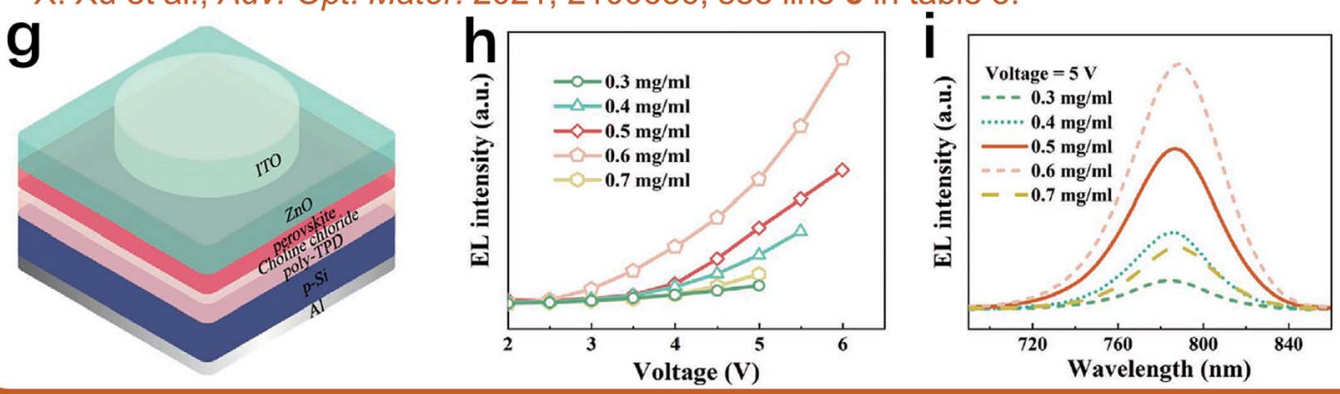

Fig. 11 (a, d, g) Schematic image of inorganic perovskite QDs/Si LEDs. (b, c, e, f, h, i) Performance of LEDs. (b) Electroluminescence (EL) spectra of $\mathrm{CsPbBr}_{3}$ QDs LEDs at different injection current, inset shows emission photograph of the $\mathrm{CsPbBr}_{3}$ QDs LEDs at $60 \mathrm{~mA}$. (c) EL spectra of CsPbl 3 QDs LEDs at different injection current. The inset shows the emission photograph of the LEDs. (e and f) Power density and EQE as a function of voltage for $\mathrm{CsPb}_{3}$ QDs LEDs. (h and i) EL intensity as a function of voltage and wavelength. $(\mathrm{a}-\mathrm{c})^{25}$ Reproduced with permission. Copyright 2018 , Wiley-VCH. $(\mathrm{d}-\mathrm{f})^{132}$ Reproduced with permission. Copyright 2018, Wiley-VCH. (g-i) ${ }^{26}$ Reproduced with permission. Copyright 2021, Wiley-VCH.

Sutherland et al. reported a whispering gallery mode laser by integrating $\mathrm{MAPbI}_{3}$ perovskite to silica microsphere. ${ }^{155}$ Silica microsphere served as high-finesse optical feedback by confining the emitted light from halide perovskites around the microsphere circumference based on total internal reflection. Yakunin et al. reported the same mode laser by drop-casting $\mathrm{CsPbX}_{3}$ nanocrystals perovskites on silica microspheres. ${ }^{\mathbf{1 5 6}}$ Tang et al. fabricated $\mathrm{CsPbX}_{3}$ microsphere with tuneable sizes and obtained a WGM microcavities laser with narrow line width $(\sim 0.09 \mathrm{~nm})$ at room temperature (see Fig. $12 \mathrm{a}) .{ }^{137}$ In addition to the microsphere, $\mathrm{MAPbI}_{3}$ disc laser was integrated on a silicon nitride photonic waveguide platform. ${ }^{163}$ The lasers show a record low lasing threshold of $4.7 \mu \mathrm{J} \mathrm{cm}^{-2}$ and a line width of $1.1 \mathrm{~nm}$ at room temperature. Perovskite laser arrays with WGM were fabricated on Si-based materials. Liu et al. reported WG mode laser array with tuneable spectrum by growing $\mathrm{MAPbI}_{3}$ platelets on a silicon substrate. ${ }^{157}$ The growth nucleus not only provides epitaxial growth of the perovskite, but also provides better optical confinement for lasing. The $\mathrm{CH}_{3} \mathrm{NH}_{3} \mathrm{PbI}_{3}$ microplates laser array presents both good crystalline and high optical quality. WG mode laser from these perovskite platelets present $1210 \mathrm{Q}$ factor. The perovskite platelet array size was controlled by changing the edge length of the patterned substrate. The laser spectrum shifts to the lower energy region when edge length of perovskite platelet is increased. The results demonstrated that a single mode laser could be obtained by shorting the cavity size or though breaking the symmetry of the cavity. Duan et al. reported $\mathrm{CH}_{3} \mathrm{NH}_{3} \mathrm{PbBr}_{3}$ microdisks (MDs) based WG mode laser. The $\mathrm{CH}_{3} \mathrm{NH}_{3} \mathrm{PbBr}_{3}$ MDs arrays with uniform sizes were formed by spin-coating $\mathrm{CH}_{3} \mathrm{NH}_{3} \mathrm{PbBr}_{3}$ perovskite films onto $\mathrm{SiO}_{2}$ MDs arrays. ${ }^{160}$ The surface tension forced the liquids to assemble at the center of the $\mathrm{SiO}_{2} \mathrm{MDs}$, leading to a microdome on the top of each silica MDs. The obtained MDs arrays of $\mathrm{CH}_{3} \mathrm{NH}_{3} \mathrm{PbBr}_{3}$ are extremely uniform in 
Table 4 Summary of Si-based perovskite lasers reported in recent years ${ }^{a}$

\begin{tabular}{|c|c|c|c|c|c|c|c|}
\hline Number & Perovskite & \multirow{2}{*}{$\begin{array}{l}\text { Device structure } \\
\text { Si/perovskite }\end{array}$} & \multicolumn{3}{|c|}{ Wavelength } & \multicolumn{2}{|c|}{$\Delta \lambda(\mathrm{nm})$ Year/ref. } \\
\hline 1 & $\mathrm{MAPbI}_{3}$ nanoplatelets & & WGM & $780-790$ & $40 \mu \mathrm{J} \mathrm{cm}^{-2}$ & 0.9 & 2014 (ref. 109) \\
\hline 3 & $\mathrm{CsPbX}_{3}$ nanocrystals & $\mathrm{SiO}_{2}$ sphere/perovskite & WGM & $440-700$ & $5 \mu \mathrm{J} \mathrm{cm}^{-2}$ & $\begin{array}{l}0.15- \\
0.2\end{array}$ & 2015 (ref. 156) \\
\hline 4 & $\mathrm{MAPbI}_{3}$ microplatelet & $\begin{array}{l}\mathrm{Si} / \mathrm{SiO}_{2} / \text { patterned h-BN/ } \\
\text { perovskite }\end{array}$ & WGM & 770 & $37 \mu \mathrm{J} \mathrm{cm}^{-2}$ & 5.4 & 2016 (ref. 157) \\
\hline 6 & $\mathrm{MAPbI}_{3}$ film & $\mathrm{Si} / \mathrm{SiO}_{2} / \mathrm{Si}_{3} \mathrm{~N}_{4} /$ perovskite & $\mathrm{PhC}$ & 780 & $200 \mu \mathrm{J} \mathrm{cm}^{-2}$ & - & 2016 (ref. 27) \\
\hline 7 & $\mathrm{MAPbI}_{3}$ grating & Si grating $/ \mathrm{Au} / \mathrm{Al}_{2} \mathrm{O}_{3} /$ perovskite & DFB & 777.6 & $5 \mathrm{~kW} \mathrm{~cm}^{-2}$ & 1.1 & 2016 (ref. 159) \\
\hline 8 & $\mathrm{MAPbBr}_{3}$ microdisks & $\mathrm{SiO}_{2}$ microdisks/perovskite & WGM & $550-560$ & $3.5 \mu \mathrm{J} \mathrm{cm}{ }^{-2}$ & - & 2017 (ref. 160) \\
\hline 9 & $\mathrm{CsPbBr}_{3}$ microsphere & $\mathrm{Si} /$ perovskite & WGM & $425-715$ & $0.42 \mu \mathrm{J} \mathrm{cm}^{-2}$ & 0.09 & 2017 (ref. 137) \\
\hline 10 & $\mathrm{MAPbI}_{3}$ film & $\mathrm{Si} / \mathrm{SiO}_{2} / \mathrm{Si}_{3} \mathrm{~N}_{4} /$ perovskite/PMMA & $\mathrm{PhC}$ & $780-791.5$ & $19.6 \mu \mathrm{J} \mathrm{cm}^{-2}$ & - & 2017 (ref. 161) \\
\hline 11 & $\mathrm{CsPbBr}_{3}$ nanocrystals & SiN/perovskite & $\mathrm{PhC}$ & $\sim 517$ & $150 \mathrm{~W} \mu \mathrm{m}^{-2}$ & - & 2017 (ref. 162) \\
\hline 16 & $\mathrm{CsPbBr}_{2.75} \mathrm{I}_{0.25}$ crystal & $\mathrm{Si} / \mathrm{SiO}_{2} /$ perovskite & $\mathrm{PhC}$ & 550 & - & - & 2019 (ref. 167) \\
\hline 17 & $\begin{array}{l}\mathrm{CsPbBr}_{3} \mathrm{CsPbI}_{3} \\
\text { nanocrystals }\end{array}$ & $\mathrm{SiO}_{2}$ sphere/perovskite & WGM & 527 & $750 \mu \mathrm{J} \mathrm{cm}^{-2}$ & 2 & 2020 (ref. 168) \\
\hline 18 & $\mathrm{CsPbBr}_{3}$ nanoplate & $\mathrm{Si} / \mathrm{SiO}_{2} /$ perovskite $/ \mathrm{Al}_{2} \mathrm{O}_{3}$ & WGM & $533.9 / 540.3$ & $388.2 / 129.7 \mu \mathrm{J}$ & 0.25 & 2020 (ref. 169) \\
\hline
\end{tabular}

${ }^{a}$ Notes: - not reported, WGM is whispering gallery mode, PhC is photonic crystal, DFB is distributed feedback, $\Delta \lambda$ is full width at half maximum (fwhm).

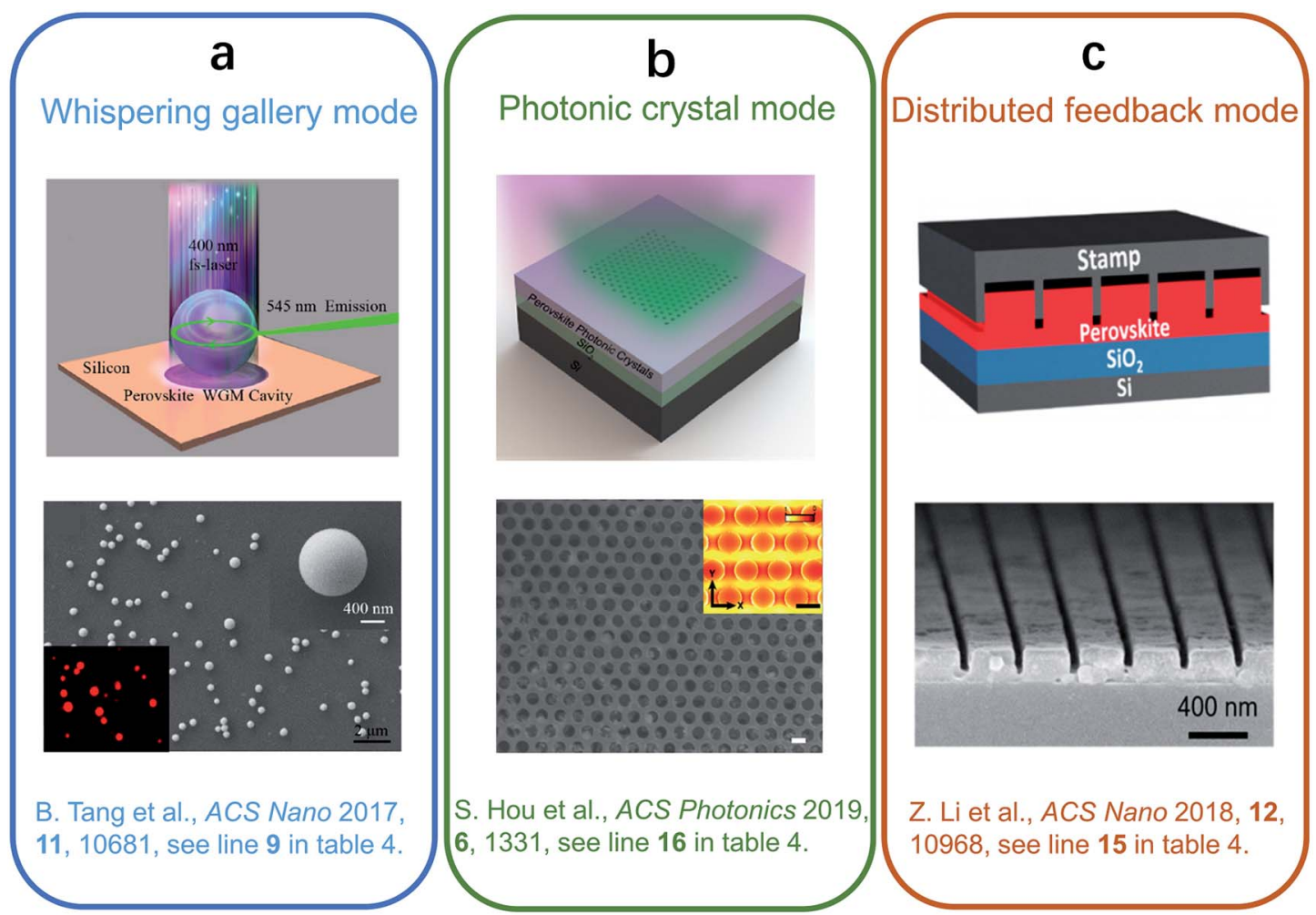

Fig. 12 (a) Schematic of perovskite whispering gallery cavity mode laser on silicon substrate and SEM image of CsPbl 3 microspheres, reproduced with permission. ${ }^{137}$ Copyright 2017, American Chemical Society. (b) Schematic of the CsPbBr $2.75 \mathrm{I}_{0.25}$ photonic crystal and SEM image of SEM image of a perovskite 2D photonic crystals, reproduced with permission. ${ }^{167}$ Copyright 2019, American Chemical Society. (c) Schematic of $\mathrm{CH}_{3} \mathrm{NH}_{3} \mathrm{Pbl}_{3}$ distributed feedback mode laser on patterned $\mathrm{Si}_{3} \mathrm{~N}_{4}$. and SEM micrograph of the device cross section, reproduced with permission. ${ }^{166}$ Copyright 2018, American Chemical Society. 
both size distribution and emission spectra. The cavity sizes and the corresponding mode numbers can be precisely changed by modifying the size of the $\mathrm{SiO}_{2}$ MDs or changing the concentration of perovskite precursor. Perovskite MDs laser arrays were also fabricated by nanoimprint lithography confining solution growth method. ${ }^{\mathbf{1 7 0}}$ The PDMS cylindricalhole-template (CHT) was obtained through casting and photolithography. Silicon with convex cylinders was used as mold. The size of convex silicon cylinders controls the diameter of PDMS CHT. The $\mathrm{CsPbCl}_{3}$ MDs present uniform sizes with a side length of $2.5 \pm 0.3 \mu \mathrm{m}$ and a thickness of $0.6 \pm 0.2 \mu \mathrm{m}$. The perovskite MDs laser spectral was controlled by ratio of halogen elements. In the issue, all inorganic perovskite lasing oscillations with tuneable emission wavelength were achieved.

\subsection{Photonic crystal bandedge mode Si-based laser}

Photonic crystal bandedge modes are generally established on both edges of a photonic bandgap at high symmetry points in the momentum space. A periodically bunched stationary field profile is the representative characteristic. Perovskite photonic crystal lasers have been reported on $\mathrm{Si}_{3} \mathrm{~N}_{4}$ waveguide platforms or $\mathrm{Si} / \mathrm{SiO}_{2}$ substrate. ${ }^{27,161,162,164}$ Cha et al. reported perovskite photonic crystal laser on $\mathrm{Si}_{3} \mathrm{~N}_{4}$ platform. ${ }^{27}$ Fig. $12 \mathrm{~b}$ presents the schematic of the $\mathrm{CH}_{3} \mathrm{NH}_{3} \mathrm{PbI}_{3}$ photonic crystal mode laser and SEM image of device cross section. The perovskite laser was realized by spin-coating perovskite film onto the $2 \mathrm{D}$ square lattice photonic crystal backbone structure fabricated on $\mathrm{Si}_{3} \mathrm{~N}_{4}$ platform. The devices exhibit a distinct laser threshold, there is a sharp emission peak on top of broad spontaneous emission. The pulse energy densities of $200 \mu \mathrm{J} \mathrm{cm}^{-2}$ at laser threshold are obtained. The perovskite photonic crystals can be well designed on Si-based substrate. Cegielski et al. reported an optically pumped $\mathrm{MAPbI}_{3}$ laser with high-throughput that was fabricated using low cost optical lithography onto a $\mathrm{Si}_{3} \mathrm{~N}_{4}$ photonic chip. ${ }^{161}$ The perovskite waveguide is fabricated by spin-coating a liquid perovskite precursor on a $\mathrm{Si}_{3} \mathrm{~N}_{4}$ photonic chip with a $\mathrm{SiO}_{2}$ cladding layer. A narrow emission spectrum upon a pump threshold fluence of $19.6 \mu \mathrm{J} \mathrm{cm} \mathrm{cm}^{-2}$ was observed at room temperature. Fig. 12b shows the schematic and SEM image of a $2 \mathrm{D} \mathrm{CsPbBr}_{2.75} \mathrm{I}_{0.25}$ photonic crystal which was fabricated by electron beam lithography and reactive ion etching on a $\mathrm{Si} / \mathrm{SiO}_{2}$ substrate. ${ }^{\mathbf{1 6 7}}$ Both the experiments and simulation further prove that the spontaneous emission rate was enhanced due to photonic bandgap effect which indued by the light energy redistribution from $2 \mathrm{D}$ guided modes to vertical direction in perovskite photonic crystals thin films. Compared to unpatterned perovskite films, the light spontaneous emission rate of perovskite photonic crystals is greatly inhibited by 7.9-fold, the PL intensity is enhanced by a factor of 23.5.

\subsection{Distributed feedback mode Si-based laser}

The characteristic of distributed feedback mode laser is Bragg scattering in interference grating which provides optical feedback for the laser. The distributed feedback mode perovskite laser could also be realized by simple progress e.g. spin-coating perovskite film onto patterned substrate. Jia et al. demonstrated distributed feedback perovskite laser constructed on a silicon substrate. ${ }^{159}$ A gold layer and an $\mathrm{Al}_{2} \mathrm{O}_{3}$ layer were pre-deposited between the perovskite and silicon substrate to maximize the thermal conductivity and minimize the surface recombination. A threshold pump intensity of $5 \mathrm{~kW} \mathrm{~cm}{ }^{-2}$ is obtained for the device. The distributed feedback resonator could be obtained by thermal nanoimprint lithography as shown in Fig. 12c. ${ }^{166}$ The device achieved an ultralow lasing threshold of $13 \mathrm{~W} \mathrm{~cm}^{-2}$. At the same time, the same group compared $\mathrm{MAPbI}_{3}$ distributed feedback cavity with the pristine thin film photoluminescence spectrum, ${ }^{165}$ a 16 -fold reduction in emission linewidth was observed. The device with directly patterned perovskite resonator showed room temperature operation. The research of perovskite laser arrays on Si-based photonic nanostructures not only enabled silicon based light sources, but also promoted applications in high throughput bio-sensing and highresolution displays.

\section{Conclusions and outlook}

Controlling the preparation of perovskite materials on the dominant Si optoelectronics platform is a crucial step to realize perovskite-based practical optoelectronic devices. In recent years, the performance and technology of optoelectronic devices based on the integration of halide perovskite with Sibased materials has been substantially improved. Examples for this successful integration can be found in photovoltaics, photodetection and in light emitting applications. In photovoltaics, the key challenges of integrating the two technologies are related to the different efficiency of optical absorption and the different stability levels achieved so far. Silicon as an indirect band gap material needs to make use of sophisticated light trapping architectures based on micrometer sized pyramidal surface textures to maximize absorption around its band gap in the near infrared. This holds for single junction but also for Sibased tandem solar cells in which the Si has the job of maximizing absorption of low energy photons. Perovskites on the other hand have so far achieved the best efficiencies with solution processed films. Combining both poses challenges that have been overcome e.g. by using smaller pyramids, by only applying the texture to the back surface and by partly using evaporation for perovskite film formation. In terms of perovskite device stability, progress has been made but success is still counted in hundreds or thousands of hours of operation as opposed to decades of lifetime as in Si photovoltaics. Though efficiencies of perovskite/Si tandem solar cells have improved considerably during the last few years, there are still challenges for going towards commercial applications. Textured silicon reduces reflection and enables enhanced light trapping by backscattering, but deposition of thin perovskite layers from solution onto textured silicon with typical pyramid heights of several mm remains a challenge.

For photo-FET based perovskite/Si photodetectors, Si was used as gate electrode, $\mathrm{SiO}_{2}$ was used as dielectric. The interface of Si/perovskite heterojunction can promote the separation and transmission of photo-generated carriers, which can not only broaden the light detection range, but also increase the light 
response rate. Compared with perovskite bulk counterparts, low dimensional perovskite nanocrystals such as 2D perovskites nanosheets, 1D perovskite nanowires and perovskite quantum dots have received increasing attention, mainly due to their potential for integration in photonic circuits. 2D perovskite nanosheets are compatible with the design and fabrication of thin film photoelectronic devices. 1D nanowires show greater application advantages in the metal-semiconductor-metal structure photodetectors than their polycrystalline film counterparts due to higher carrier mobility, and better charge collection. Inorganic halide perovskite quantum dots exhibit higher stability than their organic-inorganic hybrid counterparts. However, low-dimensional perovskite based photodetectors are still in early stage. The structure-property relationships of low dimensional perovskite need further exploring, aiming to make a balance amount of responsivity, stability and cost.

Halide perovskite quantum dots were also employed as emissive layers in LEDs and lasers. Both Si-based perovskite LEDs and perovskite/Si lasers were reported by integrating halide perovskite with silicon-based materials. P-type Si has also been used directly as functional element in LEDs by using it as hole transport layer in perovskite LEDs. These devices demonstrated that using $\mathrm{Si}$ as a functional layer can enable high efficiency and good stability in perovskite LEDs. Though Si-based perovskite LEDs have achieved green light emission, red light emission and NIR emission the technology is still at a comparably early stage. Substantial challenges that will be subject of future work are to improve their luminescence quantum efficiency to approach that of LEDs with organic transport layers. Furthermore, like in most perovskite-based applications, the device stability is insufficient. Another urgent problem is to decrease the leakage current and enhanced the light extraction rate.

For perovskite/Si laser, Si-based photonic nanostructures were used as a template to fabricate patterned perovskite laser arrays. The combination of perovskites with Si-based photonic nanostructures has enabled silicon-based light sources. However, the scalable fabrication of patterned single-crystal perovskites is still a challenge, especially for nanostructures with large aspect ratios. In order to obtained perovskite nanolaser arrays with high density and uniform lasing wavelength, the challenge of overcoming the incompatibility of perovskites with the typical lithographic process has to be urgently tackled.

\section{Conflicts of interest}

There are no conflicts to declare.

\section{Acknowledgements}

This work has been partially supported by the National Key R\&D Program of China (2018YFC0910600); the National Natural Science Foundation of China (61775145/61525503/ 61620106016/61835009); Key Project of Department of Education of Guangdong Province (2016KCXTD007); the authors acknowledge also support from the Impuls-und Vernetzungsfonds der Helmholtz Gemeinschaft via the project PEROSEED. We thank J. Hüpkes for carefully reading the manuscript.

\section{References}

1 N. M. Haegel, H. Atwater Jr, T. Barnes, C. Breyer, A. Burrell, Y. M. Chiang, S. D. Wolf, B. Dimmler, D. Feldman, S. Glunz, J. C. Goldschmidt, D. Hochschild, R. Inzunza, I. Kaizuka, B. Kroposki, S. Kurtz, S. Leu, R. Margolis, K. Matsubara, A. Metz, W. K. Metzger, M. Morjaria, S. Niki, S. Nowak, I. M. Peters, S. Philipps, T. Reindl, A. Richter, D. Rose, K. Sakurai, R. Schlatmann, M. Shikano, W. Sinke, R. Sinton, B. J. Stanbery, M. Topic, W. Tumas, Y. Ueda, J. Lagemaat, P. Verlinden, M. Vetter, E. Warren, M. Werner, M. Yamaguchi and A. W. Bett, Science, 2019, 364, 836-838.

2 A. K. Katiyar, K. Y. Thai, W. S. Yun, J. Lee and J. Ahn, Sci. Adv., 2020, 6, b576.

3 A. Goetzberger and C. Hebling, Sol. Energy Mater. Sol. Cells, 2000, 62, 1-19.

4 R. Chen, T. D. Tran, K. W. Ng, W. S. Ko, L. C. Chuang, F. G. Sedgwick and C. Chang-Hasnain, Nat. Photonics, 2011, 5, 170-175.

5 J. Justice, C. Bower, M. Meitl, M. B. Mooney, M. A. Gubbins and B. Corbett, Nat. Photonics, 2012, 6, 610-614.

6 Y. Huang, J. Yan, C. Ma and G. Yang, Nanoscale, 2019, 11, 16299-16307.

7 A. Melianas, F. Etzold, T. J. Savenije, F. Laquai, O. Inganäs and M. Kemerink, Nat. Commun., 2015, 6, 1-8.

8 T. Leijtens, K. A. Bush, R. Prasanna and M. D. McGehee, Nat. Energy, 2018, 3, 828-838.

9 E. C. Garnett, B. Ehrler, A. Polman and E. Alarcon-Llado, ACS Photonics, 2021, 8, 61-70.

10 S. Essig, C. Allebé, T. Remo, J. F. Geisz, M. A. Steiner, K. Horowitz, L. Barraud, J. S. Ward, M. Schnabel, A. Descoeudres, D. L. Young, M. Woodhouse, M. Despeisse, C. Ballif and A. Tamboli, Nat. Energy, 2017, 2, 1-9.

11 G. Xing, N. Mathews, S. S. Lim, N. Yantara, X. Liu, D. Sabba, M. Grätzel, S. Mhaisalkar and T. C. Sum, Nat. Mater., 2014, 13, 476-480.

12 D. Shi, V. Adinolfi, R. Comin, M. Yuan, E. Alarousu, A. Buin, Y. Chen, S. Hoogland, A. Rothenberger, K. Katsiev, Y. Losovyj, X. Zhang, P. A. Dowben, O. F. Mohammed, E. H. Sargent and O. M. Bakr, Science, 2015, 347, 519-522.

13 E. Koren, E. Lortscher, C. Rawlings, A. W. Knoll and U. Duerig, Science, 2015, 348, 679-683.

14 Q. Dong, Y. Fang, Y. Shao, P. Mulligan, J. Qiu, L. Cao and J. Huang, Science, 2015, 347, 967-970.

15 N. Wang, L. Cheng, R. Ge, S. Zhang, Y. Miao, W. Zou, C. Yi, Y. Sun, Y. Cao, R. Yang, Y. Wei, Q. Guo, Y. Ke, M. Yu, Y. Jin, Y. Liu, Q. Ding, D. Di, L. Yang, G. Xing, H. Tian, C. Jin, F. Gao, R. H. Friend, J. Wang and W. Huang, Nat. Photonics, 2016, 10, 699-704.

16 J. Hebig, I. Kühn, J. Flohre and T. Kirchartz, ACS Energy Lett., 2016, 1, 309-314.

17 T. Kirchartz, T. Markvart, U. Rau and D. A. Egger, J. Phys. Chem. Lett., 2018, 9, 939-946.

18 Z. Liu, L. Krückemeier, B. Krogmeier, B. Klingebiel, J. A. Márquez, S. Levcenko, S. Öz, S. Mathur, U. Rau, 
T. Unold and T. Kirchartz, ACS Energy Lett., 2019, 4, 110117.

19 L. Krückemeier, B. Krogmeier, Z. Liu, U. Rau and T. Kirchartz, Adv. Energy Mater., 2021, 2003489.

20 C. C. Boyd, R. Cheacharoen, T. Leijtens and M. D. McGehee, Chem. Rev., 2019, 119, 3418-3451.

21 J. Li, H. L. Cao, W. B. Jiao, Q. Wang, M. Wei, I. Cantone, J. Lü and A. Abate, Nat. Commun., 2020, 11, 310.

22 D. Moia and J. Maier, ACS Energy Lett., 2021, 6, 1566-1576.

23 E. Aydin, T. G. Allen, M. De Bastiani, L. Xu, J. Ávila, M. Salvador, E. Van Kerschaver and S. De Wolf, Nat. Commun., 2020, 5, 851-859.

24 T. Kirchartz, S. Korgitzsch, J. Hüpkes, C. O. R. Quiroz and C. J. Brabec, ACS Energy Lett., 2018, 3, 1861-1867.

25 J. Liu, X. Sheng, Y. Wu, D. Li, J. Bao, Y. Ji, Z. Lin, X. Xu, L. Yu, J. Xu and K. Chen, Adv. Opt. Mater., 2018, 6, 1700897.

26 X. Xu, K. Xiao, G. Hou, Y. Zhang, T. Zhu, L. Xu, J. Xu and K. Chen, Adv. Opt. Mater., 2021, 2100636.

27 H. Cha, S. Bae, M. Lee and H. Jeon, Appl. Phys. Lett., 2016, 108, 181104.

28 N. Zhang, W. Sun, S. P. Rodrigues, K. Wang, Z. Gu, S. Wang, W. Cai, S. Xiao and Q. Song, Adv. Mater., 2017, 29, 1606205.

29 M. Green, E. Dunlop, J. Hohl-Ebinger, M. Yoshita, N. Kopidakis and X. Hao, Prog. Photovoltaics, 2021, 29, 3-15. 30 T. Kirchartz, Philos. Trans. R. Soc., A, 2019, 377, 20180286.

31 K. Yoshikawa, H. Kawasaki, W. Yoshida, T. Irie, K. Konishi, K. Nakano, T. Uto, D. Adachi, M. Kanematsu, H. Uzu and K. Yamamoto, Nat. Energy, 2017, 2, 17032.

32 M. Nakamura, K. Yamaguchi, Y. Kimoto, Y. Yasaki, T. Kato and H. Sugimoto, IEEE J. Photovolt., 2019, 9, 1863.

33 Q. Liu, Y. Jiang, K. Jin, J. Qin, J. Xu, W. Li, J. Xiong, J. Liu, Z. Xiao, K. Sun, S. Yang, X. Zhang and L. Ding, Sci. Bull., 2020, 65, 272.

34 O. Almora, D. Baran, G. C. Bazan, C. Berger, C. I. Cabrera, K. R. Catchpole, S. E. Ela, F. Guo, J. Hauch, A. W. Y. HoBaillie, T. J. Jacobsson, R. A. J. Janssen, T. Kirchartz, N. Kopidakis, Y. Li, M. A. Loi, R. R. Lunt, X. Mathew, M. D. McGehee, J. Min, D. B. Mitzi, M. K. Nazeeruddin, J. Nelson, A. F. Nogueira, U. W. Paetzold, N. G. Park, B. P. Rand, U. Rau, H. J. Snaith, E. Unger, L. V. Roca, H. L. Yip and C. J. Brabec, Adv. Energy Mater., 2021, 11, 2002774.

35 B. M. Kayes, H. Nie, R. Twist, S. G. Spruytte, F. Reinhardt, I. C. Kizilyalli and G. S. Higashi, Proceedings of the 37 th IEEE Photovoltaic Specialists Conference (PVSC), 2011, pp. 4-8.

36 First Solar Press Release, First solar achieves yet another cell conversion efficiency world record, 24 February 2016.

37 R. Komiya, A. Fukui, N. Murofushi, N. Koide, R. Yamanaka and H. Katayama, Technical Digest, 21st International Photovoltaic Science and Engineering Conference, 2011, November, 2C-5O-08.

38 M. Jeong, I. W. Choi, E. M. Go, Y. Cho, M. Kim, B. Lee, S. Jeong, Y. Jo, H. W. Choi, J. Lee, J. H. Bae, S. K. Kwak, D. S. Kim and C. Yang, Science, 2020, 369, 1615-1620.

39 H. Sai, T. Matsui, H. Kumagai and K. Matsubara, Appl. Phys. Express, 2018, 11, 022301.
40 L. Krückemeier, U. Rau, M. Stolterfoht and T. Kirchartz, Adv. Energy Mater., 2020, 10, 1902573.

41 T. Kirchartz and U. Rau, Adv. Energy Mater., 2018, 8, 1703385.

42 M. Jošt, E. Köhnen, A. B. Morales-Vilches, B. Lipovšek, K. Jäger, B. Macco, A. Al-Ashouri, J. Krč, L. Korte, B. Rech, R. Schlatmann, M. Topič, B. Stannowski and S. Albrecht, Energy Environ. Sci., 2018, 11, 3511-3523.

43 F. Sahli, J. Werner, B. A. Kamino, M. Bräuninger, R. Monnard, B. Paviet-Salomon, L. Barraud, L. Ding, J. J. Diaz Leon, D. Sacchetto, G. Cattaneo, M. Despeisse, M. Boccard, S. Nicolay, Q. Jeangros, B. Niesen and C. Ballif, Nat. Mater., 2018, 17, 820-826.

44 J. J. Yoo, G. Seo, M. R. Chua, T. G. Park, Y. l. Lu, F. Rotermund, Y. K. Kim, C. Su Moon, N. J. Jeon, J. P. C. Baena, V. Bulović, S. S. Shin, M. G. Bawendi and J. Seo, Nature, 2021, 590, 587-593.

45 J. Jeong, M. Kim, J. Seo, H. Lu, P. Ahlawat, A. Mishra, Y. Yang, M. A. Hope, F. T. Eickemeyer, M. Kim, Y. J. Yoon, I. W. Choi, B. P. Darwich, S. J. Choi, Y. Jo, J. H. Lee, B. Walker, S. M. Zakeeruddin, L. Emsley, U. Rothlisberger, A. Hagfeldt, D. S. Kim, M. Grätzel and J. Y. Kim, Nature, 2021, 592, 381-385.

46 A. Richter, R. Müller, J. Benick, F. Feldmann1, B. Steinhauser, C. Reichel, A. Fell, M. Bivour, M. Hermle and S. W. Glunz, Nat. Energy, 2021, 6, 429-438.

47 A. R. Bowman, F. Lang, Y. Chiang, A. Jiménez-Solano, K. Frohna, G. E. Eperon, E. Ruggeri, M. Abdi-Jalebi, M. Anaya, B. V. Lotsch and S. D. Stranks, ACS Energy Lett., 2021, 6, 612-620.

48 A. Pusch, P. Pearce and N. J. Ekins-Daukes, IEEE J. Photovolt., 2019, 3, 679-687.

49 B. Ehrler, E. Alarcón-Lladó, S. W. Tabernig, T. Veeken, E. C. Garnett and A. Polman, ACS Energy Lett., 2020, 5, 3029-3033.

50 M. Jošt, L. Kegelmann, L. Korte and S. Albrecht, Adv. Energy Mater., 2020, 10, 1904102.

51 H. Shen, D. Walter, Y. Wu, K. C. Fong, D. A. Jacobs, T. Duong, J. Peng, K. Weber, T. P. White and K. R. Catchpole, Adv. Energy Mater., 2020, 10, 1902840.

52 A. Richter, R. Müller, J. Benick, F. Feldmann, B. Steinhauser, C. Reichel, A. Fell, M. Bivour, M. Hermle and S. W. Glunz, Nat. Energy, 2021, 6, 429.

53 A. Al-Ashouri, E. Köhnen, B. Li, A. Magomedov, H. Hempel, P. Caprioglio, J. A. Márquez, A. B. M. Vilches, E. Kasparavicius, J. A. Smith, N. Phung, D. Menzel, M. Grischek, L. Kegelmann, D. Skroblin, C. Gollwitzer, T. Malinauskas, M. Jošt, G. Matic, B. Rech, R. Schlatmann, M. Topic, L. Korte, A. Abate, B. Stannowski, D. Neher, M. Stolterfoht, T. Unold, V. Getautis and S. Albrecht, Science, 2020, 370, 1300-1309. 54 R. Fan, N. Zhou, L. Zhang, R. Yang, Y. Meng, L. Li, T. Guo, Y. Chen, Z. Xu, G. Zheng, Y. Huang, L. Li, L. Qin, X. Qiu, Q. Chen and H. Zhou, Sol. RRL, 2017, 1, 1700149.

55 Y. Wu, D. Yan, J. Peng, T. Duong, Y. Wan, S. P. Phang, H. Shen, N. Wu, C. Barugkin, X. Fu, S. Surve, D. Grant, 
D. Walter, T. P. White, K. R. Catchpole and K. J. Weber, Energy Environ. Sci., 2017, 10, 2472-2479.

56 K. A. Bush, A. F. Palmstrom, Z. J. Yu, M. Boccard, R. Cheacharoen, J. P. Mailoa, D. P. McMeekin, R. L. Z. Hoye, C. D. Bailie, T. Leijtens, I. M. Peters, M. C. Minichetti, N. Rolston, R. Prasanna, S. Sofia, D. Harwood, W. Ma, F. Moghadam, H. J. Snaith, T. Buonassisi, Z. C. Holman, S. F. Bent and M. D. McGehee, Nat. Energy, 2017, 2, 17009.

57 S. Zhu, F. Hou, W. Huang, X. Yao, B. Shi, Q. Ren, J. Chen, L. Yan, S. An, Z. Zhou, H. Ren, C. Wei, Q. Huang, Y. Li, G. Hou, X. Chen, Y. Ding, G. Wang, B. Li, Y. Zhao and X. Zhang, Sol. RRL, 2018, 2, 1800176.

58 Z. Qiu, Z. Xu, N. Li, N. Zhou, Y. Chen, X. Wan, J. Liu, N. Li, X. Hao, P. Bi, Q. Chen, B. Cao and H. Zhou, Nano Energy, 2018, 53, 798-807.

59 K. A. Bush, S. Manzoor, K. Frohna, Z. J. Yu, J. A. Raiford, A. F. Palmstrom, H. Wang, R. Prasanna, S. F. Bent, Z. C. Holman and M. D. McGehee, ACS Energy Lett., 2018, 3, 2173-2180.

60 L. Mazzarella, Y. H. Lin, S. Kirner, A. B. Morales Vilches, L. Korte, S. Albrecht, E. Crossland, B. Stannowski, C. Case, H. J. Snaith and R. Schlatmann, Adv. Energy Mater., 2019, 9, 1803241.

61 C. U. Kim, J. C. Yu, E. D. Jung, I. Y. Choi, W. Park, H. Lee, I. Kim, D. Lee, K. K. Hong, M. H. Song and K. J. Choi, Nano Energy, 2019, 60, 213-221.

62 E. Kohnen, M. Jǒst, A. B. Morales-Vilches, P. Tockhorn, A. Al-Ashouri, B. Macco, L. Kegelmann, B. Rech, R. Schlatmann, B. Stannowski and S. Albrecht, Sustainable Energy Fuels, 2019, 3, 1995-2005.

63 B. Chen, Z. Yu, K. Liu, X. Zheng, Y. Liu, J. Shi, D. Spronk, P. N. Rudd, Z. Holman and J. Huang, Joule, 2019, 3, 177190.

64 Y. Hou, E. Aydin, M. De Bastiani, C. Xiao, F. H. Isikgor, D. Xue, B. Chen, H. Chen, B. Bahrami, A. H. Chowdhury, A. Johnston, S. Baek, Z. Huang, M. Wei, Y. Dong, J. Troughton, R. Jalmood, A. J. Mirabelli, T. G. Allen, E. Van Kerschaver, M. I. Saidaminov, D. Baran, Q. Qiao, K. Zhu, S. De Wolf and E. H. Sargent, Science, 2020, 367, 1135-1140.

65 E. Lamanna, F. Matteocci, E. Calabrò, L. Serenelli, E. Salza, L. Martini, F. Menchini, M. Izzi, A. Agresti, S. Pescetelli, S. Bellani, A. E. Del Río Castillo, F. Bonaccorso, M. Tucci and A. Di Carlo, Joule, 2020, 4, 865-881.

66 D. Kim, H. J. Jung, I. J. Park, B. W. Larson, S. P. Dunfield, C. Xiao, J. Kim, J. Tong, P. Boonmongkolras, S. G. Ji, F. Zhang, S. R. Pae, M. Kim, S. B. Kang, V. Dravid, J. J. Berry, J. Y. Kim, K. Zhu, D. H. Kim and B. Shin, Science, 2020, 368, 155-160.

67 K. Wang, G. Xing, Q. Song and S. Xiao, Adv. Mater., 2020, 2000306.

68 G. E. Eperon, M. T. Hörantner and H. J. Snaith, Nat. Rev. Chem., 2017, 1, 0095.

69 S. Albrecht and B. Rech, Nat. Commun., 2017, 2, 16196.

70 J. J. Yoo, S. Wieghold, M. C. Sponseller, M. R. Chua, S. N. Bertram, N. T. P. Hartono, J. S. Tresback,
E. C. Hansen, J. Correa-Baena, V. Bulović, T. Buonassisi, S. S. Shin and M. G. Bawendi, Energy Environ. Sci., 2019, 12, 2192-2199.

71 Q. Jiang, Y. Zhao, X. Zhang, X. Yang, Y. Chen, Z. Chu, Q. Ye, X. Li, Z. Yin and J. You, Nat. Photonics, 2019, 13, 460-466.

72 X. Zheng, Y. Hou, C. Bao, J. Yin, F. Yuan, Z. Huang, K. Song, J. Liu, J. Troughton, N. Gasparini, C. Zhou, Y. Lin, D. Xue, B. Chen, A. K. Johnston, N. Wei, M. N. Hedhili, M. Wei, A. Y. Alsalloum, P. Maity, B. Turedi, C. Yang, D. Baran, T. D. Anthopoulos, Y. Han, Z. Lu, O. F. Mohammed, F. Gao, E. H. Sargent and O. M. Bakr, Nat. Commun., 2020, 5, 131-140.

73 Z. Liu, J. Siekmann, B. Klingebiel, U. Rau and T. Kirchartz, Adv. Energy Mater., 2021, 2003386.

74 D. P. McMeekin, G. Sadoughi, W. Rehman, G. E. Eperon, M. Saliba, M. T. Hörantner, A. Haghighirad, N. Sakai, L. Korte, B. Rech, M. B. Johnston, L. M. Herz and H. J. Snaith, Science, 2016, 351, 151-155.

75 J. Xu, C. C. Boyd, Z. J. Yu, A. F. Palmstrom, D. J. Witter, B. W. Larson, R. M. France, J. Werner, S. P. Harvey, E. J. Wolf, W. Weigand, S. Manzoor, M. F. A. M. van Hest, J. J. Berry, J. M. Luther, Z. C. Holman and M. D. McGehee, Science, 2020, 367, 1097-1104.

76 J. P. Mailoa, C. D. Bailie, E. C. Johlin, E. T. Hoke, A. J. Akey, W. H. Nguyen, M. D. McGehee and T. Buonassisi, Appl. Phys. Lett., 2015, 106, 121105.

77 M. Köhler, M. Pomaska, P. Procel, R. Santbergen, A. Zamchiy, B. Macco, A. Lambertz, W. Duan, P. Cao, B. Klingebiel, S. Li, A. Eberst, M. Luysberg, K. Qiu, O. Isabella, F. Finger, T. Kirchartz, U. Rau and K. Ding, Nat. Energy, 2021, 6, 529.

78 G. Nogay, F. Sahli, J. Werner, R. Monnard, M. Boccard, M. Despeisse, F. J. Haug, Q. Jeangros, A. Ingenito and C. Ballif, ACS Energy Lett., 2019, 4, 844-845.

79 B. Chen, Z. J. Yu, S. Manzoor, S. Wang, W. Weigand, Z. Yu, G. Yang, Z. Ni, X. Dai, Z. C. Holman and J. Huang, Joule, 2020, 4, 850-864.

80 L. Zhou, R. Wang, C. Yao, X. Li, C. Wang, X. Zhang, C. Xu, A. Zeng, D. Zhao and F. Zhang, Nat. Commun., 2015, 6, 6938.

81 A. Armin, R. D. Jansen-van Vuuren, N. Kopidakis, P. L. Burn and P. Meredith, Nat. Commun., 2015, 6, 6343.

82 R. D. Jansen-van Vuuren, A. Armin, A. K. Pandey, P. L. Burn and P. Meredith, Adv. Mater., 2016, 28, 4766-4802.

83 F. H. L. Koppens, T. Mueller, P. Avouris, A. C. Ferrari, M. S. Vitiello and M. Polini, Nat. Nanotechnol., 2014, 9, 780-793.

84 J. Liu, Y. Xue, Z. Wang, Z. Xu, C. Zheng, B. Weber, J. Song, Y. Wang, Y. Lu, Y. Zhang and Q. Bao, ACS Nano, 2016, 10, 3536-3542.

85 W. Deng, X. Zhang, L. Huang, X. Xu, L. Wang, J. Wang, Q. Shang, S. Lee and J. Jie, Adv. Mater., 2016, 28, 2201-2208.

86 H. Deng, X. Yang, D. Dong, B. Li, D. Yang, S. Yuan, K. Qiao, Y. Cheng, J. Tang and H. Song, Nano Lett., 2015, 15, 79637969.

87 J. Song, L. Xu, J. Li, J. Xue, Y. Dong, X. Li and H. Zeng, Adv. Mater., 2016, 28, 4861-4868. 
88 X. Li, D. Yu, F. Cao, Y. Gu, Y. Wei, Y. Wu, J. Song and H. Zeng, Adv. Funct. Mater., 2016, 26, 5903-5912.

89 A. Waleed, M. M. Tavakoli, L. Gu, Z. Wang, D. Zhang, A. Manikandan, Q. Zhang, R. Zhang, Y. Chueh and Z. Fan, Nano Lett., 2016, 17, 523-530.

90 D. H. Kwak, D. H. Lim, H. S. Ra, P. Ramasamy and J. S. Lee, RSC Adv., 2016, 6, 65252-65256.

91 M. Shoaib, X. Zhang, X. Wang, H. Zhou, T. Xu, X. Wang, X. Hu, H. Liu, X. Fan, W. Zheng, T. Yang, S. Yang, Q. Zhang, X. Zhu, L. Sun and A. Pan, J. Am. Chem. Soc., 2017, 139, 15592-15595.

92 W. Deng, L. Huang, X. Xu, X. Zhang, X. Jin, S. Lee and J. Jie, Nano Lett., 2017, 17, 2482-2489.

93 X. Liu, D. Yu, F. Cao, X. Li, J. Ji, J. Chen, X. Song and H. Zeng, Small, 2017, 13, 1700364.

94 Y. Chen, Y. Chu, X. Wu, W. Ou-Yang and J. Huang, Adv. Mater., 2017, 29, 1704062.

95 T. Yang, Y. Zheng, Z. Du, W. Liu, Z. Yang, F. Gao, L. Wang, K. Chou, X. Hou and W. Yang, ACS Nano, 2018, 12, 1611-1617. 96 J. Feng, C. Gong, H. Gao, W. Wen, Y. Gong, X. Jiang, B. Zhang, Y. Wu, Y. Wu, H. Fu, L. Jiang and X. Zhang, Nat. Electron., 2018, 1, 404-410.

97 H. Wu, H. Si, Z. Zhang, Z. Kang, P. Wu, L. Zhou, S. Zhang, Z. Zhang, Q. Liao and Y. Zhang, Adv. Sci., 2018, 5, 1801219.

98 W. Zhai, J. Lin, C. Li, S. Hu, Y. Huang, C. Yu, Z. Wen, Z. Liu, Y. Fang and C. Tang, Nanoscale, 2018, 10, 21451-21458.

99 Y. Zhou, J. Luo, Y. Zhao, C. Ge, C. Wang, L. Gao, C. Zhang, M. Hu, G. Niu and J. Tang, Adv. Opt. Mater., 2018, 6, 1800679.

100 B. Pradhan, G. S. Kumar, S. Sain, A. Dalui, U. K. Ghorai, S. K. Pradhan and S. Acharya, Chem. Mater., 2018, 30, 2135-2142.

101 Y. Meng, C. Lan, F. Li, S. Yip, R. Wei, X. Kang, X. Bu, R. Dong, H. Zhang and J. C. Ho, ACS Nano, 2019, 13, 6060-6070.

102 Y. Zhao, Y. Qiu, H. Gao, J. Feng, G. Chen, L. Jiang and Y. Wu, Adv. Mater., 2020, 32, 1905298.

103 G. Chen, J. Feng, H. Gao, Y. Zhao, Y. Pi, X. Jiang, Y. Wu and L. Jiang, Adv. Funct. Mater., 2019, 29, 1808741.

104 Y. Yang, H. Dai, F. Yang, Y. Zhang, D. Luo, X. Zhang, K. Wang, X. W. Sun and J. Yao, Nanoscale Res. Lett., 2019, 14, 291.

105 M. Gong, R. Sakidja, R. Goul, D. Ewing, M. Casper, A. Stramel, A. Elliot and J. Z. Wu, ACS Nano, 2019, 13, 1772-1783.

106 T. Yang, X. Wang, B. Zheng, Z. Qi, C. Ma, Y. Fu, Y. Fu, M. P. Hautzinger, Y. Jiang, Z. Li, P. Fan, F. Li, W. Zheng, Z. Luo, J. Liu, B. Yang, S. Chen, D. Li, L. Zhang, S. Jin and A. Pan, ACS Nano, 2019, 13, 7996-8003.

107 S. Parveen, K. K. Paul and P. K. Giri, ACS Appl. Mater. Interfaces, 2020, 12, 6283-6297.

108 W. Niu, A. Eiden, G. Vijaya Prakash and J. J. Baumberg, Appl. Phys. Lett., 2014, 104, 171111.

109 Q. Zhang, S. T. Ha, X. Liu, T. C. Sum and Q. Xiong, Nano Lett., 2014, 14, 5995-6001.

110 R. Su, C. Diederichs, J. Wang, T. C. H. Liew, J. Zhao, S. Liu, W. Xu, Z. Chen and Q. Xiong, Nano Lett., 2017, 17, 39823988.
111 S. T. Ha, X. Liu, Q. Zhang, D. Giovanni, T. C. Sum and Q. Xiong, Adv. Opt. Mater., 2014, 2, 838-844.

112 Q. Liao, K. Hu, H. Zhang, X. Wang, J. Yao and H. Fu, Adv. Mater., 2015, 27, 3405-3410.

113 Y. Gao, E. Shi, S. Deng, S. B. Shiring, J. M. Snaider, C. Liang, B. Yuan, R. Song, S. M. Janke, A. Liebman-Peláez, P. Yoo, M. Zeller, B. W. Boudouris, P. Liao, C. Zhu, V. Blum, Y. Yu, B. M. Savoie, L. Huang and L. Dou, Nat. Chem., 2019, 11, 1151-1157.

114 J. Feng, X. Yan, Y. Liu, H. Gao, Y. Wu, B. Su and L. Jiang, Adv. Mater., 2017, 29, 1605993.

115 K. Hong, Q. V. Le, S. Y. Kim and H. W. Jang, J. Mater. Chem. C, 2018, 6, 2189-2229.

116 L. Gao, K. Zeng, J. Guo, C. Ge, J. Du, Y. Zhao, C. Chen, H. Deng, Y. He, H. Song, G. Niu and J. Tang, Nano Lett., 2016, 16, 7446-7454.

117 L. Zhu, Q. Lai, W. Zhai, B. Chen and Z. L. Wang, Mater. Today, 2020, 37, 56-63.

118 D. H. Lim, P. Ramasamy, D. H. Kwak and J. S. Lee, Nanotechnology, 2017, 28, 255601.

119 D. Zhang, Y. Yang, Y. Bekenstein, Y. Yu, N. A. Gibson, A. B. Wong, S. W. Eaton, N. Kornienko, Q. Kong, M. Lai, A. P. Alivisatos, S. R. Leone and P. Yang, J. Am. Chem. Soc., 2016, 138, 7236-7239.

120 X. He, P. Liu, S. Wu, Q. Liao, J. Yao and H. Fu, J. Mater. Chem. C, 2017, 5, 12707.

121 J. K. Meyers, S. Kim, D. J. Hill, E. E. M. Cating, L. J. Williams, A. S. Kumbhar, J. R. McBride, J. M. Papanikolas and J. F. Cahoon, Nano Lett., 2017, 17, 7561-7568.

122 C. Bao, J. Yang, S. Bai, W. Xu, Z. Yan, Q. Xu, J. Liu, W. Zhang and F. Gao, Adv. Mater., 2018, 30, 1803422.

123 F. Liu, Y. Zhang, C. Ding, S. Kobayashi, T. Izuishi, N. Nakazawa, T. Toyoda, T. Ohta, S. Hayase, T. Minemoto, K. Yoshino, S. Dai and Q. Shen, ACS Nano, 2017, 11, 10373-10383.

124 Y. Wang and H. Sun, Small Methods, 2018, 2, 1700252.

125 P. Ramasamy, D. Lim, B. Kim, S. Lee, M. Lee and J. Lee, Chem. Commun., 2016, 52, 2067-2070.

126 J. Lu, X. Sheng, G. Tong, Z. Yu, X. Sun, L. Yu, X. Xu, J. Wang, J. Xu, Y. Shi and K. Chen, Adv. Mater., 2017, 29, 1700400.

127 L. Protesescu, S. Yakunin, M. I. Bodnarchuk, F. Krieg, R. Caputo, C. H. Hendon, R. X. Yang, A. Walsh and M. V. Kovalenko, Nano Lett., 2015, 15, 3692-3696.

128 G. Li, F. W. R. Rivarola, N. J. L. K. Davis, S. Bai, T. C. Jellicoe, F. de la Peña, S. Hou, C. Ducati, F. Gao, R. H. Friend, N. C. Greenham and Z. Tan, Adv. Mater., 2016, 28, 3528-3534.

129 W. Xu, Q. Hu, S. Bai, C. Bao, Y. Miao, Z. Yuan, T. Borzda, A. J. Barker, E. Tyukalova, Z. Hu, M. Kawecki, H. Wang, Z. Yan, X. Liu, X. Shi, K. Uvdal, M. Fahlman, W. Zhang, M. Duchamp, J. Liu, A. Petrozza, J. Wang, L. Liu, W. Huang and F. Gao, Nat. Photonics, 2019, 13, 418-424.

130 T. Chiba1, Y. Hayashi, H. Ebe, K. Hoshi, J. Sato, S. Sato, Y. J. Pu, S. Ohisa and J. Kido, Nat. Photonics, 2018, 12, 681-687.

131 Y. Dong, Y. K. Wang, F. Yuan, A. Johnston, Y. Liu, D. Ma, M.-J. Choi, B. Chen, M. Chekini, S.-W. Baek, L. K. Sagar, 
J. Fan, Y. Hou, M. Wu, S. Lee, B. Sun, S. Hoogland, R. Quintero-Bermudez, H. Ebe, P. Todorovic, F. Dinic, P. Li, H. T. Kung, M. I. Saidaminov, E. Kumacheva, E. Spiecker, L.-S. Liao, O. Voznyy, Z. H. Lu and E. H. Sargent, Nat. Nanotechnol., 2020, 15, 668-674.

132 J. Liu, X. Zhang, Y. Ji, X. Sheng, H. Ma, X. Xu, L. Yu, J. Xu and K. Chen, Adv. Opt. Mater., 2018, 6, 1800693.

133 J. Liu, Z. Lu, X. Zhang, Y. Zhang, H. Ma, Y. Ji, X. Xu, L. Yu, J. Xu and K. Chen, Nanomaterials, 2018, 8, 974.

134 X. Liu, D. Yu, C. Huo, X. Song, Y. Gao, S. Zhang and H. Zeng, Adv. Opt. Mater., 2018, 1800206.

135 Q. Zhang, R. Su, X. Liu, J. Xing, T. C. Sum and Q. Xiong, Adv. Funct. Mater., 2016, 26, 6238-6245.

136 H. Zhu, Y. Fu, F. Meng, X. Wu, Z. Gong, Q. Ding, M. V. Gustafsson, M. T. Trinh, S. Jin and X. Zhu, Nat. Mater., 2015, 14, 636-642.

137 B. Tang, H. Dong, L. Sun, W. Zheng, Q. Wang, F. Sun, X. Jiang, A. Pan and L. Zhang, ACS Nano, 2017, 11, 1068110688.

138 K. Wang, S. Sun, C. Zhang, W. Sun, Z. Gu, S. Xiao and Q. Song, Mater. Chem. Front., 2017, 1, 477-481.

139 N. Pourdavoud, T. Haeger, A. Mayer, P. J. Cegielski, A. L. Giesecke, R. Heiderhoff, S. Olthof, S. Zaefferer, I. Shutsko, A. Henkel, D. Becker-Koch, M. Stein, M. Cehovski, O. Charfi, H. Johannes, D. Rogalla, M. C. Lemme, M. Koch, Y. Vaynzof, K. Meerholz, W. Kowalsky, H. Scheer, P. Görrn and T. Riedl, Adv. Mater., 2019, 31, 1903717.

140 H. Cha, S. Bae, H. Jung, M. J. Ko and H. Jeon, Adv. Opt. Mater., 2017, 5, 1700545.

141 J. Zhao, Y. Yan, C. Wei, W. Zhang, Z. Gao and Y. S. Zhao, Nano Lett., 2018, 18, 1241-1245.

142 K. Wang, W. Sun, J. Li, Z. Gu, S. Xiao and Q. Song, ACS Photonics, 2016, 3, 1125-1280.

143 H. Dong, C. Zhang, X. Liu, J. Yaoab and Y. S. Zhao, Chem. Soc. Rev., 2020, 49, 951-982.

144 Q. Shang, M. Li, L. Zhao, D. Chen, S. Zhang, S. Chen, P. Gao, C. Shen, J. Xing, G. Xing, B. Shen, X. Liu and Q. Zhang, Nano Lett., 2020, 20, 6636-6643.

145 Q. Zhang, Q. Shuang, R. Su, T. T. H. Do and Q. Xiong, Nano Lett., 2021, 21, 1903-1914.

146 D. H. Nguyen, J. Y. Sun, C. Y. Lo, J. M. Liu, W. S. Tsai, M. H. Li, S. J. Yang, C. C. Lin, S. D. Tzeng, Y. R. Ma, M. Y. Lin and C. C. Lai, Adv. Mater., 2021, 33, 2006819.

147 L. Lei, Q. Dong, K. Gundogdu and F. So, Adv. Funct. Mater., 2021, 31, 2010144.

148 F. Deschler, M. Price, S. Pathak, L. E. Klintberg, D. Jarausch, R. Higler, S. Hüttner, T. Leijtens, S. D. Stranks, H. J. Snaith, M. Atatüre, R. T. Phillips and R. H. Friend, J. Phys. Chem. Lett., 2014, 5, 1421-1426.

149 T. S. Kao, Y. Hong, K. Hong and T. Lu, Nanotechnology, 2021, 32, 282001.

150 P. Brenner, M. Stulz, D. Kapp, T. Abzieher, U. W. Paetzold, A. Quintilla, I. A. Howard, H. Kalt and U. Lemmer, Appl. Phys. Lett., 2016, 109, 141106.
151 A. Pan, W. Zhou, E. S. P. Leong, R. Liu, A. H. Chin, B. Zou and C. Z. Ning, Nano Lett., 2009, 9, 784-788.

152 Y. S. Zhao, A. Peng, H. Fu, Y. Ma and J. Yao, Adv. Mater., 2008, 20, 1661-1665.

153 T. Rauch, M. Böberl, S. F. Tedde, J. Fürst, M. V. Kovalenko, G. Hesser, U. Lemmer, W. Heiss and O. Hayden, Nat. Photonics, 2009, 3, 332.

154 D. Xing, C. C. Lin, Y. L. Ho, A. S. A. Kamal, I. T. Wang, C. C. Chen, C. Y. Wen, C. W. Chen and J. J. Delaunay, Adv. Funct. Mater., 2020, 31, 2006283.

155 B. R. Sutherland, S. Hoogland, M. M. Adachi, C. T. O. Wong and E. H. Sargent, ACS Nano, 2014, 8, 10947.

156 S. Yakunin, L. Protesescu, F. Krieg, M. I. Bodnarchuk, G. Nedelcu, M. Humer, G. De Luca, M. Fiebig, W. Heiss and M. V. Kovalenko, Nat. Commun., 2015, 6, 8056.

157 X. Liu, L. Niu, C. Wu, C. Cong, H. Wang, Q. Zeng, H. He, Q. Fu, W. Fu, T. Yu, C. Jin, Z. Liu and T. C. Sum, Adv. Sci., 2016, 3, 1600137.

158 K. Wang, Z. Gu, S. Liu, W. Sun, N. Zhang, S. Xiao and Q. Song, J. Phys. Chem. Lett., 2016, 7, 2549-2555.

159 Y. Jia, R. A. Kerner, A. J. Grede, A. N. Brigeman, B. P. Rand and N. C. Giebink, Nano Lett., 2016, 16, 4624-4629.

160 Z. Duan, Y. Wang, G. Li, S. Wang, N. Yi, S. Liu, S. Xiao and Q. Song, Laser Photonics Rev., 2017, 12, 1700234.

161 P. J. Cegielski, S. Neutzner, C. Porschatis, H. Lerch, J. Bolten, S. Suckow, A. R. S. Kandada, B. Chmielak, A. Petrozza, T. Wahlbrink and A. L. Giesecke, Opt. Express, 2017, 25, 13199.

162 Z. Yang, M. Pelton, M. I. Bodnarchuk, M. V. Kovalenko and E. Waks, Appl. Phys. Lett., 2017, 111, 221104.

163 P. J. Cegielski, A. L. Giesecke, S. Neutzner, C. Porschatis, M. Gandini, D. Schall, C. A. R. Perini, J. Bolten, S. Suckow, S. Kataria, B. Chmielak, T. Wahlbrink, A. Petrozza and M. C. Lemme, Nano Lett., 2018, 18, 69156923.

164 Q. Shang, S. Zhang, Z. Liu, J. Chen, P. Yang, C. Li, W. Li, Y. Zhang, Q. Xiong, X. Liu and Q. Zhang, Nano Lett., 2018, 18, 3335-3343.

165 A. Gharajeh, R. Haroldson, Z. Li, J. Moon, B. Balachandran, W. Hu, A. Zakhidov and Q. Gu, Opt. Lett., 2018, 43, 611-614.

166 Z. Li, J. Moon, A. Gharajeh, R. Haroldson, R. Hawkins, W. Hu, A. Zakhidov and Q. Gu, ACS Nano, 2018, 12, 10968-10976.

167 S. Hou, A. Xie, Z. Xie, L. Y. M. Tobing, J. Zhou, L. Tjahjana, J. Yu, C. Hettiarachchi, D. Zhang, C. Dang, E. H. T. Teo, M. D. Birowosuto and H. Wang, ACS Photonics, 2019, 6, 1331-1337.

168 M. B. Price, K. Lewellen, J. Hardy, S. M. Lockwood, C. Zemke-Smith, I. Wagner, M. Gao, J. Grand, K. Chen, J. M. Hodgkiss, E. L. Ru and N. J. L. K. Davis, J. Phys. Chem. Lett., 2020, 11, 7009-7014.

169 H. Yu, X. Xu, H. Liu, Y. Wan, X. Cheng, J. Chen, Y. Ye and L. Dai, ACS Nano, 2020, 14, 552-558.

170 X. He, P. Liu, H. Zhang, Q. Liao, J. Yao and H. Fu, Adv. Mater., 2017, 29, 1604510. 